This is the submitted version of the following article:

Meitzner R., Faber T., Alam S., Amand A., Roesch R., Büttner M., Herrmann-Westendorf F., Presselt M., Ciammaruchi L., Visoly-Fisher I., Veenstra S., Diaz de Zerio A., Xu X., Wang E., Müller C., Troshin P., Hager M.D., Köhn S., Dusza M., Krassas M., Züfle . Impact of P3HT materials properties and layer architecture on OPV device stability. Solar Energy Materials and Solar Cells, (2019). 202. 110151: - .

10.1016/j. solmat.2019.110151,

which has been published in final form at https://dx.doi.org/10.1016/j.solmat.2019.110151 (c) https://dx.doi.org/10.1016/j.solmat.2019.110151. This manuscript version is made available under the CC-BY-NC-ND 4.0 license http://creativecommons. org/licenses/by-nc-nd/4.0/ 


\section{Impact of P3HT Materials Properties and Layer Architecture on OPV Device Stability}

Rico Meitzner ${ }^{1,2}$, Tobias Faber ${ }^{3}$, Shahidul Alam ${ }^{1,2}$, Roland Roesch ${ }^{1,2}$, Mathias Büttner ${ }^{3}$, Felix Herrmann-Westendorf ${ }^{4}$, Martin Presselt ${ }^{1,4,19,20}$, Laura Ciammaruchi ${ }^{5}{ }^{*}$, Iris Visoly-Fisher, ${ }^{5,6}$ Sjoerd Veenstra ${ }^{7}$, Amaia Diaz de Zerio ${ }^{8}$, Xiaofeng Xu ${ }^{8}$, Ergang Wang ${ }^{8}$, Christian Müller ${ }^{8}$, Pavel Troshin $^{9 a}$, 9b , Martin D. Hager ${ }^{1,2}$, Sandra Köhn ${ }^{1,2}$, Michal Dusza ${ }^{10,11}$, Miron Krassas ${ }^{12}$, Simon Züfle $^{16,17}$, E. Kymakis ${ }^{12}$, Eugene A. Katz ${ }^{5,6}$, Solenn Berson ${ }^{13}$, Filip Granek ${ }^{10}$, Matthieu Manceau $^{13}$, Francesca Brunetti ${ }^{14}$,Giuseppina Polino ${ }^{14,18}$, Ulrich S. Schubert ${ }^{1,2}$, Monica LiraCantu $^{15}$, and Harald Hoppe ${ }^{1,2}$

${ }^{1}$ Center for Energy and Environmental Chemistry Jena (CEEC Jena), Friedrich Schiller University Jena, Philosophenweg 7a, 07743 Jena, Germany

${ }^{2}$ Laboratory of Organic and Macromolecular Chemistry (IOMC), Friedrich Schiller University Jena, Humboldstrasse 10, 07743 Jena, Germany

${ }^{3}$ Institute of Physics, Technische Universität Ilmenau, Weimarer Straße 32, 98693 Ilmenau, Germany

${ }^{4}$ Institute of Physical Chemistry (IPC), Friedrich Schiller University Jena, Helmholtzweg 4, 07743 Jena, Germany

${ }^{5}$ Department of Sol. Energ. and Environmental Physics, Swiss Inst. for Dryland Environmental and Energy Research, J. Blaustein Institutes for Desert Research, Ben-Gurion University of the Negev, Midreshet Ben-Gurion 8499000, Israel

${ }^{6}$ Ilse Katz Institute for Nanoscale Science and Technology, Ben-Gurion University of the Negev, Beersheva 8410501, Israel

${ }^{7}$ ECN/Solliance, High Tech Campus 21, 5656 AE Eindhoven, The Netherlands

${ }^{8}$ Department of Chemistry and Chemical Engineering, Chalmers University of Technology, 41296 Göteborg, Sweden

${ }^{9 a}$ Skolkovo Institute of Science and Technology, Nobel st. 3, Moscow, 121205, Russia

${ }^{9 b}$ IPCP RAS, Semenov Prospect 1, Chernogolovka, 141432, Russia.

${ }^{10}$ Wroclaw Research Centre EIT+, Stablowicka 147, 54-066 Wroclaw, Poland

${ }^{11}$ Institute of Low Temperature and Structure Research, Polish Academy of Science, Okolna 2, 50-422 Wroclaw, Poland

${ }^{12}$ Center of Materials Technology and Photonics, Electrical Engineering Department, School of Applied Technology, Technological Educational Institute (TEI) of Crete, Heraklion, 71004 Crete, Greece

${ }^{13}$ CEA, LITEN/DTS, Laboratoire des technologies pour les Modules Photovoltaïques, Savoie Technolac, BP 332, 50 Avenue du Lac Léman, 73377 Le Bourget-du-Lac, France

${ }^{14}$ CHOSE (Centre for Hybrid and Organic Sol. Energ.), Department of Electronic Engineering, University of Rome Tor Vergata, Via del Politecnico 1, 00133, Rome, Italy

${ }^{15}$ Catalan Institute of Nanoscience and Nanotechnology (ICN2), Campus UAB, Bellaterra, 08193 Barcelona, Spain

${ }^{16}$ Institute of Computational Physics, Zurich University of Applied Sciences (ZHAW), Wildbachstrasse 21, 8400 Winterthur

${ }^{17}$ Fluxim AG, Katharina-Sulzer-Platz 2, 8400 Winterthur, Switzerland

${ }^{18}$ Center for Advanced Biomaterials for Healthcare, Instituto Italiano di Tecnologia, 80125 Italy

${ }^{19}$ Leibniz Institute of Photonic Technology (IPHT), Albert-Einstein-Str. 9, 07745 Jena, Germany

${ }^{20}$ sciclus GmbH \& Co. KG, Moritz-von-Rohr-Str. 1a, 07745 Jena, Germany 


\begin{abstract}
We report a cooperative study conducted between different laboratories to investigate organic solar cell degradation with respect to P3HT material properties and different solar cell architectures. Various batches of P3HT were collected from different suppliers reflecting commercial availability as well as properties variability. Among the materials properties explicitly considered were the molar mass, dispersity, regio-regularity, impurities by trace metals and intrinsic doping evaluated from radical concentrations. Each of the participating laboratories contributing test devices applied their own layer stack, i.e. their own device architecture and layout. This variation was appreciated as another parameter for evaluation. Even though a large amount of devices failed due to extrinsic degradation effects, indeed, some materials properties were found to be more important than others for obtaining long lifetimes and high stability of P3HT-based polymer solar cells.
\end{abstract}




\section{Introduction}

With increasing depletion of fossil fuels and growing strain on the environment due to emission of greenhouse gases and thereby accelerating global warming, it is necessary to switch to more renewable and sustainable ways of energy generation. As the most abundant renewable energy source on earth is sunlight, a very attractive technology for providing of sustainable energy is photovoltaics. Of these a very interesting subcategory is represented by organic photovoltaics (OPV) with its ability to rely on abundant materials, being easily scalable and bearing the potential of very high speeds in roll-to-roll processing.

Recently a significant progress was made in this field with regards to efficiency and stability. Power conversion efficiencies of 13-14\% were obtained in single junction, bulk-heterojunction organic solar cells (BHJ OSC) ${ }^{1,2}$ and operational lifetimes in the range of 10 years ${ }^{3-5}$ were estimated on the basis of exclusively intrinsic degradation processes. Roll-to-roll processed flexible modules have already demonstrated outdoor stabilities of several years ${ }^{6}$. While this is very encouraging and promising, more understanding is required in terms of how materials properties impact the device stability.

Various published reports demonstrated extrapolated operational lifetimes of OPV for several years ${ }^{4,5,7,8,11}$. A recently published review ${ }^{3,6,9}$ revealed an increase in publication activities on OPV stability research and an increase in average reported lifetimes over the recent years, clearly demonstrating progress in the field. The observed experimental lifetimes range up to 2 years ${ }^{8,10}$, when no extrapolations to $\mathrm{T}_{80}$ (corresponding to efficiency drop to $80 \%$ of the initial efficiency value) or $\mathrm{T}_{\mathrm{S}, 80}$ (corresponding to efficiency drop to $80 \%$ after stabilization) were considered ${ }^{11,12}$.

An important factor to be taken into account when evaluating the lifetime of an OPV device is the so-called burn-in phase. The burn-in is described as the initial rapid decay of the solar cell performance followed by a stabilized performance ${ }^{7,11}$. In some more recent reports devices seemed to show no burn-in ${ }^{7,13}$, but even with a burn-in, very long lifetimes are attainable ${ }^{4}$. After all, a limited performance loss during burn-in does not harm long-term energy harvesting if the performance decay thereafter is very low.

In general, degradation can be divided into intrinsic and extrinsic mechanisms ${ }^{3,14,15}$. Extrinsic mechanisms are those that can be avoided by a proper sealing of the device. Most common examples are photo-oxidation due to oxygen ingress ${ }^{16,17}$ and electrode corrosion from ingress of moisture ${ }^{14}$. These modes of degradation can be successfully prevented with a robust encapsulation of the device and they can be further alleviated by an inverted solar cell architecture, where low-workfunction metals ${ }^{18}$, which are prone to corrosion due to oxygen or moisture ingress, can be avoided. Intrinsic mechanisms, however, cannot be prevented by employing encapsulation, as they originate from the materials used in the solar cell layer stack, and are triggered by unavoidable factors such as temperature (heat) ${ }^{15,19,20}$ and electromagnetic radiation (including UV-light) ${ }^{21-23}$. Some examples are an increased phase separation of donor and acceptor in the active layer blend ${ }^{24}$, the formation of traps and increased energetic disorder $^{25,26}$, the formation of fullerene dimers ${ }^{27-29}$ and electro-migration of e.g. silver from printed electrodes ${ }^{30}$. Charge transport layers may also induce effects leading to degradation, e.g. 
doping of the photoactive layer via $\mathrm{MoO}_{3}{ }^{31,32}$. Furthermore, impurities inherently connected to the materials used, e.g. remnants from synthesis such as catalyzing agents (metal impurities) or low molar mass components may also be responsible for electronic trap formation ${ }^{33-35}$.

Besides the mentioned doping effect, transport layers degradation can also have a large impact on the overall stability of organic solar cells ${ }^{36-39}$. Degradation of the transport layers or of their interfaces can induce an extraction barrier to charge carriers ${ }^{40}$. Transport layers can be quite diverse, ranging from small molecules to polymers to amorphous or nanocrystalline metal oxides to hybrids of these materials ${ }^{41}$. A commonly used hole transport layer, PEDOT:PSS, is well known to be a potential weak point for stability, due to its hygroscopic and acidic properties ${ }^{6,42}$. Metal oxides have become very common as transport layers due to their capability to be solution processable $^{36}$ and their rather good stability ${ }^{37,43-45}$.

The most commonly studied material in OPV is poly(3-hexylthiophene) (P3HT) ${ }^{46}$, as it is relatively cheap to produce and readily available in kilogram amounts, due to easy synthetic upscaling ${ }^{47}$. In order to enable wide comparability among the researchers working in the field, in this study solar cells based on the classical material combination P3HT:PCBM $\left([6,6]-\right.$ phenyl-C $61^{-}$ butyric acid methyl ester) were explored under variation of P3HT batches in order to assess the impact of the material parameters of P3HT on device stability. Five labs were involved in providing solar cells according to their optimized layer stack architecture and device layout, constituting the second parameter space.

The phase behavior of P3HT:PCBM blends is not only controlled by miscibility, which is strongly enhanced in amorphous P3HT domains, but also by the ability of each of the two constituents to crystallize. Upon prolonged heating this may lead to crystallization induced largescale (micron-sized) phase separation. Hence material purity and regio-regularity are expected to play an important role concerning morphological stability ${ }^{48,49}$. For P3HT:PCBM solar cells also a minor voltage loss during burn-in has been observed, which was assigned to the formation of less ordered phases ${ }^{50}$.

P3HT with higher regio-regularity is reported to be relatively stable against photo-oxidation, as crystallinity hampers both the in-diffusion of reactants (oxygen) as well as conformational changes required for oxidation ${ }^{3,48}$. Molecular weight does not always seem to have an impact on photostability $^{48}$, but certainly impacts the crystallization temperature ${ }^{51}$. Though there are conflicting reports about other polymers as $\mathrm{PCDTBT}^{15}$ and $\mathrm{PTB}^{52}$ where a higher molar mass resulted in a longer lifetime, this can be most likely associated to smaller electronic trap formation at chain ends. A higher glass transition temperature $\left(T_{g}\right)$ or a higher melting point $\left(T_{m}\right)$, as described by the dispersity (PDI), were reported to exhibit a positive impact on thermal stability $^{24,53-56}$. Countermeasures against morphological degradation include the application of polymers exhibiting higher $\mathrm{T}_{\mathrm{g}}{ }^{57}$, the application of phase-locked diblock-copolymers ${ }^{58}$, acceptor alloys $^{59,60}$ as well as crosslinking of organic semiconductors ${ }^{61-64}$.

Furthermore, trace metals in the active layer could catalyze reactions or act as traps and therefore as recombination centers. Several reports ${ }^{33,65}$ mention the impact of impurities on device performance - and hence studying their impact on stability is required. 
Finally, upon analyzing all results, several recommendations could be derived for obtaining longterm stability with organic solar cells based on P3HT and potentially beyond.

\section{Experimental}

Five different commercial P3HT samples were acquired from 1M, BASF, Merck, Plextronics and Rieke Metals Inc. and named P3HT-I through P3HT-V, without following the producer order above. Commercial P3HTs were chosen to study the viability of these materials available from suppliers broadly used labs within the OPV community. Their intrinsic properties were evaluated in detail via chemical, thermal and optical analysis. Thus their properties, reported in the results section, are the only parameters to enter into the evaluation. $\mathrm{PC}_{61} \mathrm{BM}$ of $99 \%$ purity or better was used in all cases for the suppliers of the used $\mathrm{PC}_{61} \mathrm{BM}$ see Table 2.

In Figure 1 the procedure of the initial experimental phase, including ordering and distribution of P3HTs, manufacturing of the solar cells and characterization, is depicted. Chemical characterization including ${ }^{1} \mathrm{H}$ nuclear magnetic resonance spectroscopy, size exclusion chromatography, induction coupled plasma optical emission spectroscopy, electron spin resonance spectroscopy, thermal characterization like differential scanning calorimetry and thermogravimetric analysis, as well as optical characterization methods like UV/Vis spectroscopy and photothermal deflection spectroscopy, were performed. Additionally, electronic characterization including current-voltage (IV) and external quantum efficiency (EQE) measurements, as well as different characterization methods performed with PAIOS by Fluxim (see section 2.7.3), were done. The results of these experiments are reported in Sections 2.6 and 2.7.

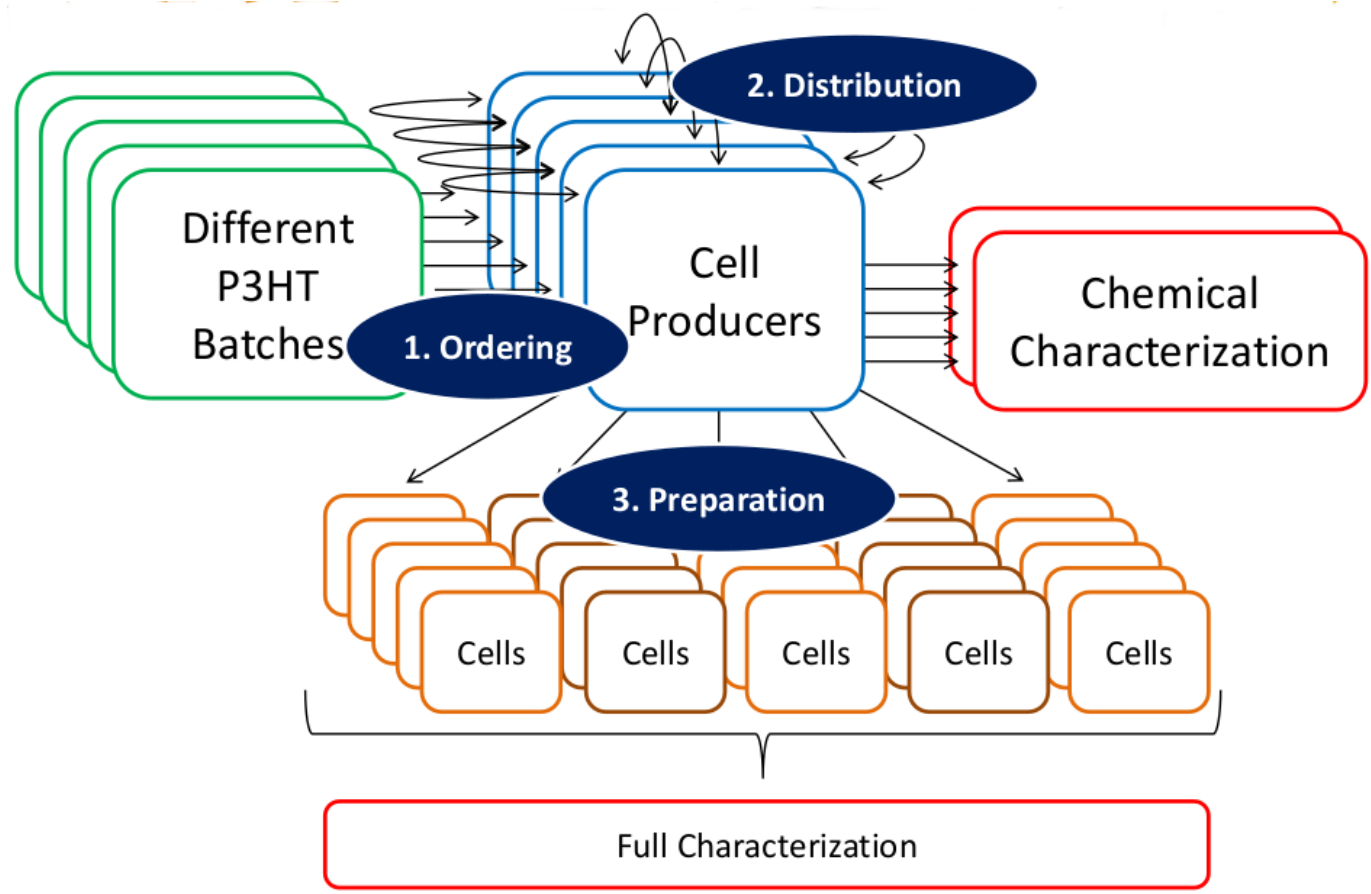

Figure 1: Schematic of the experimental proceedings before aging. 
In Figure 2 the experimental procedure after cell manufacturing and initial characterization is shown. The produced solar cell devices (see section 2.1) were distributed to the respective labs for aging (see section 2.3) and some were sent to Fluxim for characterization with the PAIOS instrument. Aging was performed at different labs according to ISOS-L2, ISOS-D2 and ISOS-O1 protocols ${ }^{12}$, as explained in detail in Section 2.3. Samples aged at L2, D2 and O1 were also sent to Fluxim after aging to determine their electrical properties.

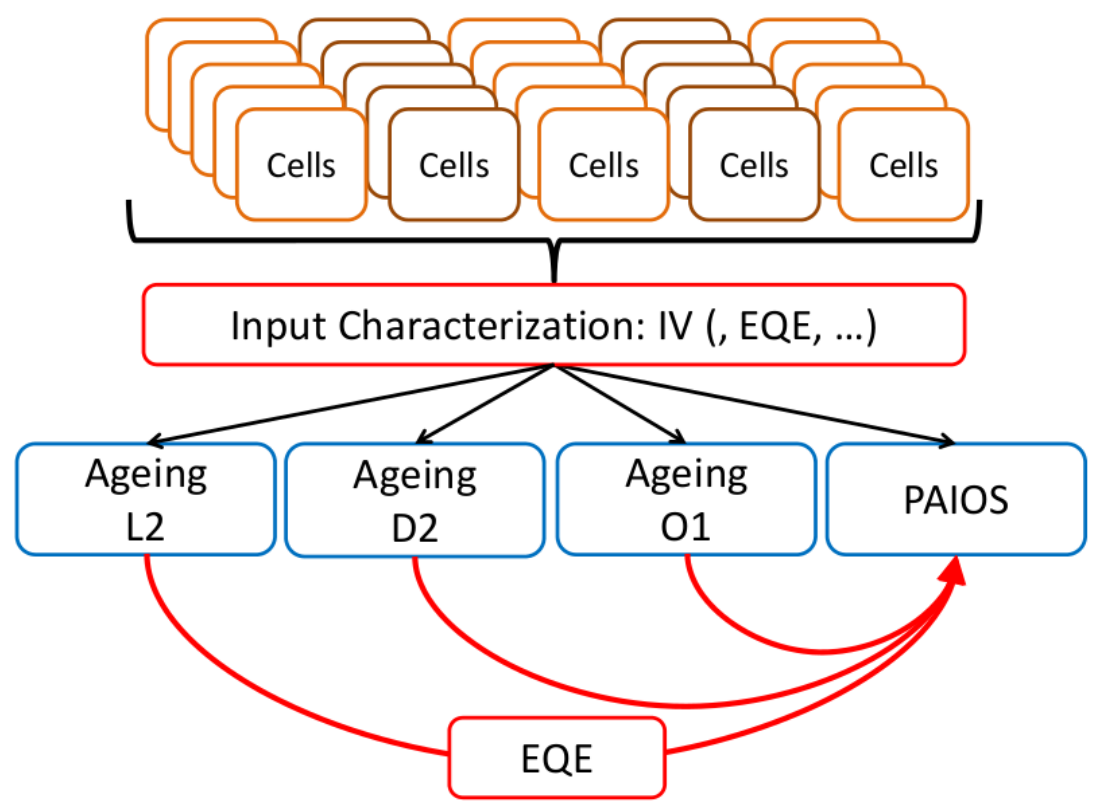

Figure 2: Further experimental procedure after production and initial characterization of the devices.

At the end of the experiment the polymer properties determined from chemical and thermal analysis were correlated with the extracted lifetime parameters. For ease of reading the results, a unified color code for the different P3HT batches was defined and is shown in Table 1 .

Table 1: Color coding for the materials used in the experiment.

\begin{tabular}{ll}
\hline Material & Color Code \\
\hline P3HT-I & Black \\
\hline P3HT-II & Red \\
\hline P3HT-III & Blue \\
\hline P3HT-IV & Green \\
\hline P3HT-V & Orange \\
\hline
\end{tabular}

\subsection{Materials and Layer Stacks}

We deliberately allowed a large variation in layer stacks/device layout- including substrates providing additional parameters impacting device stability. This was made possible by the fact that each cell producer prepared devices based on all the different P3HT batches using their preferred device layout. Five different labs served as cell producers: Commissariat à l'énergie atomique et aux énergies alternatives (CEA), Wroclaw Research Centre EIT+ (EIT+), Institut 
Català de Nanociència i Nanotecnologia (ICN2), Technological Educational Institute Crete (TEIC) and University Torr Vergata Rome (UTV). The different P3HT batches were contributed by different collaborators of the experiment. Three of the cell producers used ITO coated glass as substrates, one lab used FTO coated glass (ICN2), and one lab used ITO coated PET foil (CEA); suppliers can be found in the Table 2. Further variations were in the device architecture, including mainly inverted layer stacks (electron extraction via semi-transparent electrode) as well as one example for conventional layer stack (hole extraction via semi-transparent electrode). The charge extraction layers were varied as well: $\mathrm{ZnO}, \mathrm{MoO}_{3}, \mathrm{~V}_{2} \mathrm{O}_{5}$, PEIE, and PEDOT:PSS were used. Calcium, aluminum and silver served as opaque back electrodes. Three producers used epoxy as sealant for cell encapsulation (EIT+, TEIC and ICN2), while CEA used a fully flexible encapsulation and UTV used Surlyn, an ionomer for sealing. All layer stacks as well as device layouts are reported in detail in Error! Reference source not found..

Table 2: List of layer stacks and materials applied in the solar cells.

PET: polyethylene terephthalate; TCO: transparent conducting oxide; ITO: indium tin oxide; FTO: fluorine doped tin oxide; PEDOT:PSS: poly(3,4-ethylenedioxythiophene) polystyrene sulfonate; PC61BM: Phenyl-C61-butyric acid methyl ester; CB: chlorobenzene; o-DCB: orthodichlorobenzene

\begin{tabular}{|c|c|c|c|c|c|}
\hline Supplier & CEA & EIT+ & ICN2 & TEIC & UTV \\
\hline $\begin{array}{l}\text { Type of } \\
\text { architecture }\end{array}$ & Inverted & Inverted & $\begin{array}{l}\text { Inverted (No } \\
\text { UV filter) }\end{array}$ & Conventional & Inverted \\
\hline Substrate & $\begin{array}{l}\text { PET/TCO } \\
\text { (visiontek) }\end{array}$ & $\begin{array}{l}\text { Glass/ITO } \\
\text { (Ossila) }\end{array}$ & $\begin{array}{l}\text { Glass/FTO } \\
\text { (SOLEMS) }\end{array}$ & Glass/ITO & $\begin{array}{l}\text { Glass/ITO } \\
\text { (Kintec) }\end{array}$ \\
\hline ETL & $\begin{array}{l}\mathrm{ZnO} \text { (Sigma } \\
\text { Aldrich) }\end{array}$ & $\begin{array}{l}\mathrm{ZnO} \text { (Sigma } \\
\text { Aldrich) }\end{array}$ & $\begin{array}{l}\mathrm{ZnO} \text { (Sigma } \\
\text { Aldrich) }\end{array}$ & $\begin{array}{l}\text { Ca (Kurt J. } \\
\text { Lesker } \\
\text { Company) }\end{array}$ & $\begin{array}{l}\text { PEIE } \\
\text { (Sigma } \\
\text { Aldrich) }\end{array}$ \\
\hline HTL & $\begin{array}{l}\text { PEDOT:PSS } \\
\text { (Heraeus) }\end{array}$ & $\begin{array}{l}\mathrm{MoO}_{3} \\
\text { (Sigma } \\
\text { Aldrich) }\end{array}$ & $\begin{array}{l}\mathrm{V}_{2} \mathrm{O}_{5} \text { (home } \\
\text { made, } \\
\text { vanadium } \\
\text { ethoxide from } \\
\text { Sigma- } \\
\text { Aldrich)) }\end{array}$ & $\begin{array}{l}\text { PEDOT:PSS } \\
\text { (Heraeus) }\end{array}$ & $\begin{array}{l}\mathrm{MoO}_{3}(5 \mathrm{~nm} \\
\text { evaporated) } \\
\text { (Sigma } \\
\text { Aldrich) }\end{array}$ \\
\hline РCBM & $\begin{array}{l}\mathrm{PC}_{61} \mathrm{BM} \\
\text { (Merck) }\end{array}$ & $\begin{array}{l}\mathrm{PC}_{61} \mathrm{BM} \\
\text { (Lumtec) }\end{array}$ & $\begin{array}{l}\mathrm{PC}_{61} \mathrm{BM} \\
\text { (Solenne) }\end{array}$ & $\begin{array}{l}\mathrm{PC}_{61} \mathrm{BM} \\
\text { (Solenne) }\end{array}$ & $\begin{array}{c}\mathrm{PC}_{61} \mathrm{BM} \\
\text { (Solenne) }\end{array}$ \\
\hline Solvents & $\begin{array}{l}\text { CB (Sigma } \\
\text { Aldrich) }\end{array}$ & $\begin{array}{l}o-\mathrm{DCB} \\
\text { (Poch S.A.) }\end{array}$ & $\begin{array}{l}\text { CB (Sigma- } \\
\text { Aldrich) }\end{array}$ & $\begin{array}{l}o \text {-DCB } \\
\text { (Sigma } \\
\text { Aldrich) }\end{array}$ & $\mathrm{CB}$ \\
\hline $\begin{array}{l}\text { Metal } \\
\text { Electrode }\end{array}$ & Ag, evaporated & $\begin{array}{l}\text { Ag, } \\
\text { evaporated } \\
\text { (Kurt J. } \\
\text { Lesker } \\
\text { Company) }\end{array}$ & $\begin{array}{l}\text { Ag, } \\
\text { evaporated } \\
\text { (Kurt J. } \\
\text { Lesker } \\
\text { Company) }\end{array}$ & $\begin{array}{l}\text { Aluminum } \\
\text { (Kurt J. } \\
\text { Lesker } \\
\text { Company) }\end{array}$ & $\begin{array}{l}\text { Ag, } 100 \mathrm{~nm} \\
\text { evaporated } \\
\text { (Kurt J. } \\
\text { Lesker } \\
\text { Company) }\end{array}$ \\
\hline Adhesive & Thermoplastic & $\begin{array}{l}\text { Epoxy } \\
\text { (Ossila) }\end{array}$ & $\begin{array}{l}\text { Epoxy } \\
\text { (Ossila) }\end{array}$ & $\begin{array}{l}\text { Epoxy } \\
\text { (Ossila) }\end{array}$ & $\begin{array}{l}\text { Parafilm } \\
\text { (Heathrow } \\
\text { Scientific) }\end{array}$ \\
\hline Encapsulation & $\begin{array}{l}\text { Flexible } \\
\text { transparent }\end{array}$ & Glass & Glass & Glass (Ossila) & $\begin{array}{l}\text { Glass } \\
\text { (PEARL) }\end{array}$ \\
\hline
\end{tabular}


Table 3 : Producers of OPV devices, layer stack, layout (photo) and single device area.

\begin{tabular}{|c|c|c|c|}
\hline Manufacturer & Layer Stack & Photo & Active Area $\left(\mathrm{mm}^{2}\right)$ \\
\hline \multirow{6}{*}{ CEA, France } & Ag & & \multirow{6}{*}{140} \\
\hline & PEDOT:PSS & & \\
\hline & P3HT:PCBM & & \\
\hline & ZnO & & \\
\hline & TCO & & \\
\hline & PET & & \\
\hline \multirow{6}{*}{ EIT+, Poland } & Ag & & \multirow{6}{*}{4.5} \\
\hline & $\mathrm{MoO}_{3}$ & 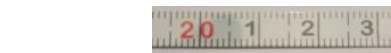 & \\
\hline & P3HT:PCBM & & \\
\hline & $\mathrm{ZnO}$ & 5 & \\
\hline & ITO & & \\
\hline & Glass & & \\
\hline \multirow{6}{*}{ ICN2, Spain } & $\mathrm{Ag}$ & & \multirow{6}{*}{20} \\
\hline & $\mathrm{V}_{2} \mathrm{O}_{5}$ & & \\
\hline & P3HT:PCBM & & \\
\hline & $\mathrm{ZnO}$ & & \\
\hline & FTO & & \\
\hline & Glass & & \\
\hline \multirow{6}{*}{ TEIC, Greece } & Al & & \multirow{6}{*}{4} \\
\hline & $\mathbf{C a}$ & & \\
\hline & P3HT:РCBM & & \\
\hline & PEDOT:PSS & & \\
\hline & ITO & $\varepsilon$ & \\
\hline & Glass & & \\
\hline \multirow{6}{*}{ UTV, Italy } & $\mathrm{Ag}$ & & \multirow{6}{*}{10} \\
\hline & $\mathrm{MoO}_{3}$ & & \\
\hline & P3HT:PCBM & & \\
\hline & PEIE & & \\
\hline & ITO & & \\
\hline & Glass & & \\
\hline
\end{tabular}

\subsection{Processing of Active Layer Solutions}

The active layer solutions were provided by various labs involved in the study and were distributed including detailed preparation recipes among all cell producers. These recipes were followed largely, though small adaptations were allowed concerning processing temperatures in order to incorporate for specific layer stack requirements. In general, solutions were handled around $50^{\circ} \mathrm{C}$ for storage and processing; details can be found in the Supporting Information. 


\subsection{Aging Methods:}

Aging of the photovoltaic devices was performed following largely the published ISOS recommendations. Three different aging protocols were applied: laboratory weathering (L2), outdoor aging (O1) and dark aging (D2). This allowed us to investigate the impact of different stress conditions on the device stability.

\subsubsection{ISOS-L2 Degradation}

Samples were aged at the CEEC Jena under conditions close to ISOS-L2. The setup in Jena consists of a metal halide lamp, whose illumination spectrum is close to AM 1.5G, as can be seen in Figure 3. The light intensity was set to $1000 \mathrm{~W} / \mathrm{m}^{2}$ with help of a pyranometer. The intensity was logged by a silicon sensor at all times, demonstrating that the operation of the lamp was very stable. The temperature was set to $55^{\circ} \mathrm{C}$ in a shady region of the chamber and monitored as well. Unfortunately, a higher temperature could not be reached and therefore remained $10 \mathrm{~K}$ below the ISOS recommendations. However, the acceleration for $10 \mathrm{~K}$ higher temperature can be estimated to be roughly a factor of two ${ }^{66}$. Furthermore, as the devices were illuminated, their temperature was considerably higher than in the shadow, yielding $65^{\circ} \mathrm{C}$ or higher inside the cells. Humidity was monitored and remained constant at around $5 \%$ r.H within the setup due to the elevated temperature. The samples were electrically connected via crocodile clamps to a multiplexing unit (Keithley 2700). Periodic current-voltage (IV) characterization was performed automatically every 30 min with a Keithley 2400 via computer control. When multiple cells on a substrate were available, the innermost cells were chosen for aging, as they were considered to be least affected by extrinsic degradation mechanisms.

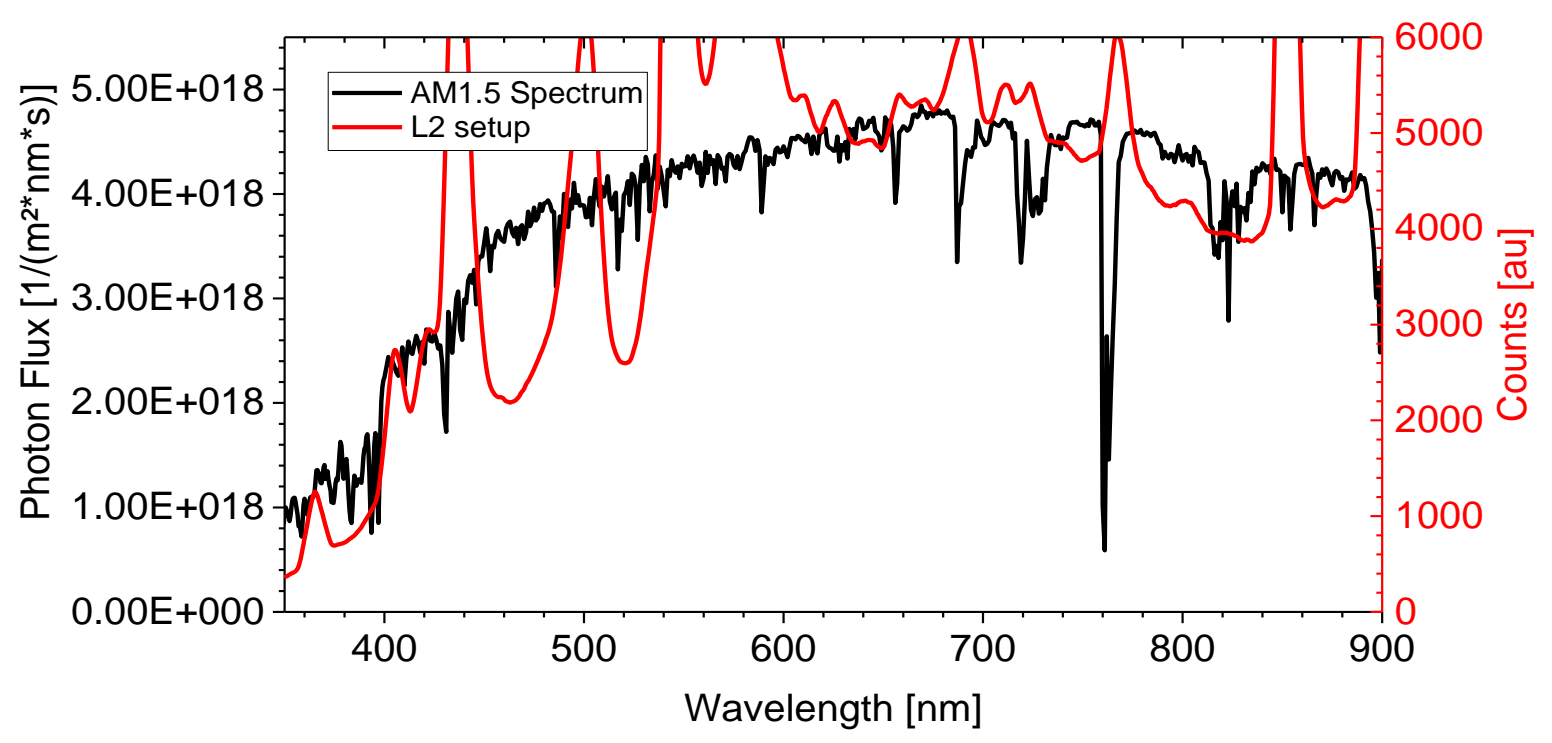

Figure 3: Comparison of the spectrum of the metal halide lamp used in the L2 aging setup at 
CEEC Jena with AM $1.5 G$ showing a good match. The full intensity range is shown in Figure S1 (Supplementary Information).

\subsection{ISOS-D2 Degradation}

Dark storage degradation was carried out Solliance in Eindhoven under a solar simulator equipped with a sulphur plasma light source (Solaronix), under which the samples were shaded by a metal plate. The samples were occasionally uncovered, computer-controlled automated IV measurements took place during the whole aging process every hour and the collected data was stored in a database. The IV measurements recorded under one sun illumination were later filtered from the complete data set. During the aging process the temperature was set to $65^{\circ} \mathrm{C}$ and relative humidity stayed at around 5\% at that temperature. The setup used and the device connections can be seen in Figure S4. Solar cells on substrates with more than one device were chosen based on maximum performance.

\subsection{ISOS-O1 Degradation}

The cells were mounted on a fixed angle ( $30^{\circ}$ to horizontal) stand (as shown in Figure S3) and the global intensity of incident sunlight was measured with a calibrated thermopile pyranometer (Eppley PSP) mounted on the same plane. It should be noted that the spectrum measured at noon time $\pm 2-3$ hours of a cloudless day at Sede Boqer, Israel (Lat. $30.8^{\circ} \mathrm{N}$, Lon. $34.8^{\circ} \mathrm{E}$, Alt. $475 \mathrm{~m}$ ), matches almost perfectly to the standardized AM $1.5 \mathrm{G}$ spectrum ${ }^{67}$, see Figure S2. The cells were exposed between November 2015 and February 2016 and only during light hours (between \pm 9:30 and 15:30) for a total of $\sim 210 \mathrm{~h}$, in order to avoid potential encapsulation breaking or contact oxidation problems due to night-time humidity. After the daily exposure the cells were stored in the dark at shelf life conditions (lab environment).

The photovoltaic parameters of the solar cells were periodically monitored indoor with an AM1.5 class AAA Newport Oriel Verasol LSH-7520 solar simulator $\left(70 \mathrm{~mW} / \mathrm{cm}^{2}\right)$ and a Keithley 2410 source-measure unit. Before aging the cells were kept in the dark inside a glove box $(\mathrm{O} 2<0.1$ ppm). 


\subsection{Materials characterization:}

\subsubsection{Dynamic Scanning Calorimetry (DSC), Size Exclusion Chromatography (SEC), Nuclear Magnetic Resonance Spectroscopy (NMR)}

Differential scanning calorimetry (DSC) was carried out under nitrogen between -20 to $300{ }^{\circ} \mathrm{C}$ at a scan rate of $10^{\circ} \mathrm{C} / \mathrm{min}$ using a Mettler Toledo DSC2 calorimeter equipped with a HSS7 sensor and a TC-125MT intracooler. DSC was used to determine the peak melting and crystallization temperature as well as the enthalpy of melting. Thermogravimetric analysis (TGA) was carried out under nitrogen between 20 to $550{ }^{\circ} \mathrm{C}$ at a scan rate of $10{ }^{\circ} \mathrm{C} / \mathrm{min}$ using a Mettler Toledo TGA/DSC 3+ instrument. TGA was used to determine the decomposition temperature. The molar mass was measured with size exclusion chromatography (SEC) on an Agilent PL-GPC 220 Integrated High Temperature GPC/SEC System in 1,2,4-trichlorobenzene at $150{ }^{\circ} \mathrm{C}$ using relative calibration with polystyrene standards. SEC was used to determine the molar mass and the dispersity (PDI) of the polymers. ${ }^{1} \mathrm{H}$ nuclear magnetic resonance (NMR) spectroscopy was measured on a Varian Inova $400 \mathrm{MHz}$ NMR spectrometer by using chloroform-d $\left(\mathrm{CDCl}_{3}\right)$ as solvent and tetramethylsilane (TMS) as internal reference. The head-to-tail (HT) and head-tohead $(\mathrm{HH})$ protons from $\alpha-\mathrm{CH}_{2}$ on the hexyl side chain give a peak at around $\delta=2.8 \mathrm{ppm}$ and $\delta=$ $2.6 \mathrm{ppm}$, respectively. The regioregularity of P3HT was calculated from the ${ }^{1} \mathrm{H}$ NMR integral of the different $\alpha-\mathrm{CH}_{2}$ protons on the hexyl of P3HT by following the equation (1) below ${ }^{68}$ :

$$
R_{P 3 H T}(\%)=\frac{\text { Integral }_{H T}}{\text { Integral }_{H T}+\text { Integral }_{H H}}
$$

\subsubsection{Inductively Coupled Plasma Optical Emission Spectroscopy (ICP-OES)}

ICP-OES was used to determine the trace metal content of the polymers. 200 to $250 \mathrm{mg}$ polymer were digested in nitric acid (65\%, purity p.A., Merck Schuchardt OHG) and hydrogen peroxide $(33 \%)$ in a microwave (Biotage Initiator+, instrument settings $15 \mathrm{~min}, 180{ }^{\circ} \mathrm{C}$, vial $0.5-2 \mathrm{~mL}$, absorption level very high, fixed hold time OFF). This process was repeated three times with altogether $2 \mathrm{~mL}$ nitric acid and $400 \mu \mathrm{L}$ hydrogen peroxide. The combined solutions were refilled to $25 \mathrm{~mL}$ with water and filtered through nylon syringe filter $(0.45 \mu \mathrm{m}$, Applichrom). The resulting solution was utilized for the measurements with the ICP-OES (Varian 725-ES) to determine the trace metal contents.

\subsubsection{Electron spin resonance (ESR)}

Standard $5 \mathrm{~mm}$ OD NMR tubes (which are ESR silent within the $\mathrm{g}=2.00$ region) were loaded with the P3HT powder (10-20 mg) inside the argon glovebox and tightly closed under inert atmosphere before taking them out for measurements. The weights of the empty sample tubes and those with the introduced material were determined with a high accuracy (+/- $0.01 \mathrm{mg})$. The ESR spectra were recorded using a benchtop Adani CMS8400 spectrometer. Integration of the signals in the ESR spectra was performed using EPR4K software developed by National Institute of Environmental Health Science (NIEHS). Each sample was characterized by average number of spins per repeating unit following the previously published approach ${ }^{65}$. 


\subsubsection{Optical Spectroscopy - Ultraviolet/Visible-Spectroscopy (UV/Vis), Photothermal Deflection Spectroscopy (PDS)}

A custom-made spectroscopy setup was used to determine UV/Vis spectra. In the setup a glass fiber above the sample, which captures light reflected from the sample, is surrounded by a ring of several other fibers which carry the light from a white light source containing a halogen lamp and a deuterium arc lamp. Below the sample there is another glass fiber collecting the light transmitted through the device. The fibers are connected to two spectrometers from Avantes AvaSpec-ULS3648, which record the spectra.

A custom-made setup for photothermal deflection spectroscopy (PDS) was used to determine the sub-bandgap absorption of all investigated P3HT films as done in previous works ${ }^{69,70,71}$. The measurement principle and basic setup of PDS is described elsewhere. ${ }^{72}$ The used monochromatic light source (obtained from LOT-Quantum Design) contains a $450 \mathrm{~W}$ Xenon lamp and a monochromator with a focal length of $260 \mathrm{~mm}$.). The monochromator is equipped with three gratings providing maximum intensity from 300 to $2000 \mathrm{~nm}$, while the resolution is kept at $10 \mathrm{~nm}$ up to $1000 \mathrm{~nm}$ and $20 \mathrm{~nm}$ above $1000 \mathrm{~nm}$. The light is modulated by a chopper operating at a frequency of $5 \mathrm{~Hz}$. Deflection of a $0.7 \mathrm{~mW}$ HeNe-laser is measured by a $10 x 10 \mathrm{~mm}^{2}$ lateral effect sensor obtained from Thorlabs. The measured deflection is frequency selective and amplified by a SR850 Lock-In amplifier. The samples are dispersed in perfluorohexane and graphite is used as standard to calibrate the data. A self-written Labview program automatically collects and calibrates the data. 


\subsection{Device characterization:}

\subsubsection{Current-Voltage-Characterization (IV)}

Devices were initially IV characterized upon arrival e.g. at CEEC Jena under a solar simulator using a metal halide lamp. The metal halide lamp was calibrated to $1000 \mathrm{~W} / \mathrm{m}^{2}$ with a pyranometer. The setup uses a computer-controlled Keithley 2400 SMU. Samples were connected using crocodile clamps.

\subsubsection{External Quantum Efficiency (EQE)}

EQE characterization of the samples was done at CEEC Jena upon arrival and after aging. The EQE setup used is a BENTHAM PVE300. EQE measurements were generally performed without additional bias light. Hence, if the device performance decays during aging, but the EQE remains constant, the loss mechanism could be due to increased bimolecular recombination or series resistance losses, only showing under higher excitation densities. On the other hand, if EQE decreased upon ageing, but photocurrent remained on a higher level within the L2-setup, the low light level conditions within the EQE measurement point to extraction problems, e.g. due to insufficient trap filling.

\subsubsection{PAIOS characterization: \\ JV, CELIV, TPC, TPV, DIT, Impedance, C-V, Temperature dependence and numerical simulation details}

Transient and impedance techniques can help to characterize charge transport. Qualitative comparison of nominally identical devices, and between fresh and aged cells may contribute to the understanding of the underlying degradation processes. Current-voltage (IV), charge extraction by linearly increasing voltage (CELIV), transient photocurrent (TPC), transient photovoltage (TPV), double injection transient (DoIT), impedance spectroscopy, capacitance voltage curves $(\mathrm{C}-\mathrm{V})$, and further optoelectrical characterization methods were performed at Fluxim AG using their All-in-one characterization platform Paios for Solar Cells ${ }^{73,74}$. For this purpose, Fluxim received a batch of fresh devices as well as aged cells from the L2 and O1 tests. The devices were illuminated with a high-power white LED (with an intensity above 1 sun illumination) allowing for pulsed and light-intensity dependent experiments.

\subsection{Analysis method for L2 aging results: Lifetime Energy Yield (LEY)}

After the experiments were finished the aging data was analyzed to extract different relevant parameters, like the end of the burn-in period (at stabilized efficiency $\left.E_{S}\right)\left(T_{S}\right)$, the lifetime $\left(T_{80}\right)$ or lifetime after stabilization $\left(\mathrm{T}_{\mathrm{S}, 80}\right)$ and the lifetime energy yield $(\mathrm{LEY})^{4,11}$. The procedure to determine the LEY was introduced by Roesch $e t a l{ }^{4}$. It was considered useful here due to its capability to depict a relevant parameter for an energy producing device, i.e. its energy output throughout its nominal lifetime. In the case of an ISOS-L2 experiment the LEY is straightforward as the light intensity is stable throughout the whole experiment. 
In case of $\mathrm{O} 1$ and D2 aging we restricted ourselves to analyze the performance decay as is. 


\section{Results and discussion}

\subsection{Polymer properties characterization}

The initial characterization concerned polymer materials properties and the corresponding parameters obtained for the different P3HT batches investigated are summarized in Table 4 The molar masses varied roughly by a factor of three, whereas the dispersity ( $\oplus$, or polydispersity index - PDI) exhibited smaller variations with values between 2.0 and 2.7. The lowest molar mass, P3HT-III exhibited also the lowest PDI - together with P3HT-I. Concerning the regioregularity (RR) generally all samples showed high values between 94\% and 96\%; only the sample with the highest molar mass and the highest PDI, P3HT-IV, had a rather low value with $90 \%$. Also for crystallization $\left(T_{\mathrm{C}}\right)$ and melting temperatures $\left(T_{\mathrm{M}}\right)$ the same sample differed considerably from the others, exhibiting the second lowest value of $T_{\mathrm{C}}=189{ }^{\circ} \mathrm{C}$ and the lowest value of $T_{\mathrm{M}}=222{ }^{\circ} \mathrm{C}$. In accordance with its low RR, P3HT-IV exhibits the lowest melting enthalpy $\left(\Delta \mathrm{H}_{\mathrm{M}}\right)$ of all samples, indicating and confirming that it is less ordered. The decomposition temperatures were - as expected for the same chemical structure - almost identical for the different P3HT batches.

Table 4: Polymer properties of the P3HT batches determined by GPC, TGA and DSC at Chalmers University.

\begin{tabular}{lllllllll}
\hline Polymer & $\begin{array}{l}\mathbf{M}_{\mathbf{n}} \\
(\mathbf{k g} / \mathbf{m o l})\end{array}$ & $\begin{array}{l}\mathbf{M}_{\mathbf{w}} \\
(\mathbf{k g} / \mathbf{m o l})\end{array}$ & $\begin{array}{l}\mathbf{D}(-) \\
{[\mathbf{P D I}]}\end{array}$ & $\mathbf{R R}(\boldsymbol{\%})$ & $\begin{array}{l}\mathbf{T}_{\mathbf{D}} \\
\left({ }^{\circ} \mathbf{C}\right)\end{array}$ & $\begin{array}{l}\mathbf{T}_{\mathbf{M}} \\
\left({ }^{\circ} \mathbf{C}\right)\end{array}$ & $\begin{array}{l}\mathbf{T}_{\mathbf{C}} \\
\left({ }^{\circ} \mathbf{C}\right)\end{array}$ & $\begin{array}{l}\Delta \mathbf{H}_{\mathbf{M}} \\
(\mathbf{J} / \mathbf{g})\end{array}$ \\
\hline P3HT-I & 30 & 59 & 2.0 & 96 & 455 & 237 & 201 & 18 \\
\hline P3HT-II & 24 & 54 & 2.3 & 94 & 455 & 227 & 184 & 17 \\
\hline P3HT-III & 11 & 22 & 2.0 & 96 & 455 & 227 & 197 & 20 \\
\hline P3HT-IV & 26 & 71 & 2.7 & 90 & 456 & 222 & 189 & 14 \\
\hline P3HT-V & 25 & 60 & 2.4 & 95 & 455 & 236 & 198 & 21 \\
\hline
\end{tabular}

\subsection{Trace metal content analysis of the P3HT batches}

The results for the trace metal content determined by ICP-OES are summarized in Table 5. They show a certain variation between the different polymer samples, which might stem from different synthetic approaches used for the polymerization, the equipment used to handle them and the purification methods applied. The standard synthetic procedures for regioregular P3HT include the McCullough method, which is a Kumada coupling, as well as the Rieke method based on activated zinc (Rieke zinc) ${ }^{75,76}$. Moreover, the Grignard metathesis reaction (GRIM) was developed by McCullogh ${ }^{77}$. All these reactions are based on nickel catalysts. Furthermore, also palladium-catalyzed reactions have been applied: Stille coupling, Suzuki coupling as well as the dehydrogenative polycondensation ${ }^{78,79}$.

For a very ubiquitous element like sodium, which is basically everywhere, there are barely any variations between the different P3HT samples. Palladium content was below the detection limit for all samples (Pd-catalyst are only used for the non-standard polymerizations). Residual palladium is known to cause shunting problems ${ }^{80}$. The nickel content, the main catalyst for the standard polymerizations (e.g., in the $\mathrm{GRIM}^{51}$ ) is also very low for all polymer samples. Only 
P3HT-I exhibited a comparably high magnesium content, which might be caused by residual magnesium salts from utilized Grignard reagents. Noteworthy, the zinc content was also rather low for all polymers. On the other hand, P3HT-IV exhibited the highest iron (Fe) content but otherwise did not differ much from all other batches. The iron could originate from the catalyst (dppf as phosphine ligand), however, this ligand is rather unusual. Alternatively, the synthesis might also have been performed in steel reactors.

Table 5: Trace metal content of the different P3HTs used in the experiment. Determined by ICPOES ( $n n=$ below detection limit).

\begin{tabular}{lllllllllll}
\hline P3HT & $\mathbf{C a}$ & $\mathbf{C u}$ & $\mathbf{F e}$ & $\mathbf{K}$ & $\mathbf{M g}$ & $\mathbf{N a}$ & $\mathbf{N i}$ & $\mathbf{P d}$ & $\mathbf{S n}$ & $\mathbf{Z n}$ \\
Batch & $\mathbf{m g} / \mathbf{L}$ & $\mathbf{m g} / \mathbf{L}$ & $\mathbf{m g} / \mathbf{L}$ & $\mathbf{m g} / \mathbf{L}$ & $\mathbf{m g} / \mathbf{L}$ & $\mathbf{m g} / \mathbf{L}$ & $\mathbf{m g} / \mathbf{L}$ & $\mathbf{m g} / \mathbf{L}$ & $\mathbf{m g} / \mathbf{L}$ & $\mathbf{m g} / \mathbf{L}$ \\
\hline Blind & 0.115 & 0.009 & 0.116 & 0.115 & 0.013 & 0.51 & $\mathrm{nn}$ & $\mathrm{nn}$ & 0.06 & 0.015 \\
Values & 0.101 & 0.008 & 0.092 & $\mathrm{nn}$ & 0.009 & 0.49 & $\mathrm{nn}$ & $\mathrm{nn}$ & 0.06 & 0.013 \\
& & & & & & & & & & \\
P3HT- & 0.806 & 0.024 & 0.083 & 0.33 & 0.481 & 3.158 & 0.046 & $\mathrm{nn}$ & 0.182 & 0.037 \\
I & 0.789 & 0.025 & 0.084 & 0.347 & 0.487 & 3.135 & 0.057 & $\mathrm{nn}$ & 0.177 & 0.038 \\
& & & & & & & & & & \\
P3HT- & 1.077 & 0.014 & 0.153 & 0.145 & 0.131 & 3.081 & 0.045 & $\mathrm{nn}$ & 0.132 & 0.024 \\
II & 1.085 & 0.014 & 0.15 & 0.168 & 0.132 & 3.082 & 0.043 & $\mathrm{nn}$ & 0.144 & 0.024 \\
& & & & & & & & & & \\
P3HT- & 1.051 & 0.01 & 0.179 & 0.173 & 0.107 & 3.41 & 0.013 & $\mathrm{nn}$ & 0.091 & 0.072 \\
III & 1.035 & 0.01 & 0.188 & 0.177 & 0.106 & 3.367 & 0.014 & $\mathrm{nn}$ & 0.078 & 0.072 \\
& & & & & & & & & & \\
P3HT- & 1.116 & 0.01 & 0.512 & 0.155 & 0.112 & 3.183 & 0.045 & $\mathrm{nn}$ & 0.068 & 0.072 \\
IV & 1.124 & 0.01 & 0.521 & 0.159 & 0.113 & 3.185 & 0.044 & $\mathrm{nn}$ & 0.076 & 0.073 \\
\hline & & & & & & & & & & \\
P3HT- & 0.934 & 0.014 & 0.203 & 0.257 & 0.093 & 3.588 & 0.031 & $\mathrm{nn}$ & 0.133 & 0.021 \\
V & 0.949 & 0.014 & 0.203 & 0.224 & 0.094 & 3.591 & 0.029 & $\mathrm{nn}$ & 0.155 & 0.022 \\
\hline
\end{tabular}

\subsection{Optical spectroscopy}

Optical spectroscopy can yield information about the crystallinity of the different P3HT batches used. In this case films were cast from pristine P3HT solutions and characterized as is. In Figure 4 P3HT-III stands out as the most crystalline batch as can be seen by the multiple distinct peaks near the absorption onset. This is consistent with its material properties as stated in Table 4, specifically the low PDI, high regio-regularity (RR) and the high melting enthalpy. ${ }^{51}$ However, the overall correlation between spectroscopic information and structural parameters reported above is not strong. In general it could be expected that more crystalline materials would be more stable and exhibit a slower degradation ${ }^{3}$, in case blend stability dominates the degradation. 

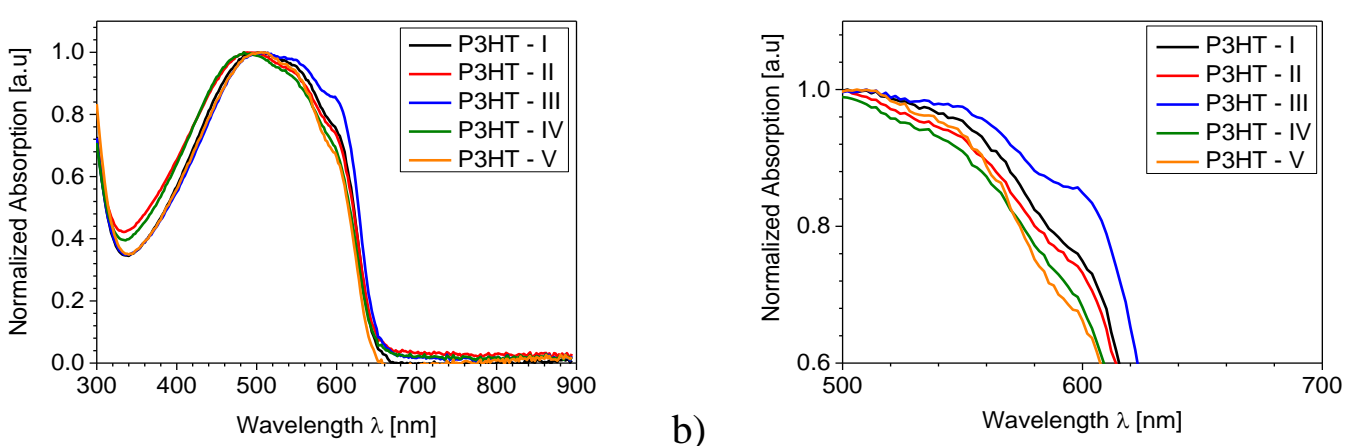

a)

b)

Figure 4: UV/Vis spectroscopy results for pristine P3HT thin films of the respective P3HT batches, a) overview and b) details of the films. P3HT-III shows the highest crystallinity.

Photothermal deflection spectroscopy, of which results are depicted in Figure 5, showed an increased absorption below the bandgap for P3HT-II, in agreement with the results from electron spin resonance spectroscopy (see below). The sub-bandgap absorption of the P3HT batches show several known features. The first one is the peak centered at around $1000 \mathrm{~nm}$ which can be assigned to the $\mathrm{P} 2$ polaron transition ${ }^{70}$, indicating minor $\mathrm{p}$-doping of all batches of the pristine P3HT. It seems that this is most pronounced for P3HT-IV, and least pronounced for P3HT-I and III. While P3HT-I contained relatively high content of trace metal impurities, P3HT-III had fewer impurities making an assignment of the polaron peak to trace metal contents difficult. However, P3HT-IV exhibited the highest content of Iron. Furthermore, we see an unstructured absorption between 700 and $900 \mathrm{~nm}$ which is most prominent in P3HT-II and -V. This might be caused by amorphous morphology resulting in increased tail absorption. ${ }^{71}$ However, interestingly, the most disordered P3HT-IV batch exhibits a lower absorption in this range. A shallow defect state arising e.g. from chemical impurities could also explain this feature, which might increase the recombination rate in $\mathrm{P} 3 \mathrm{HT}$. 


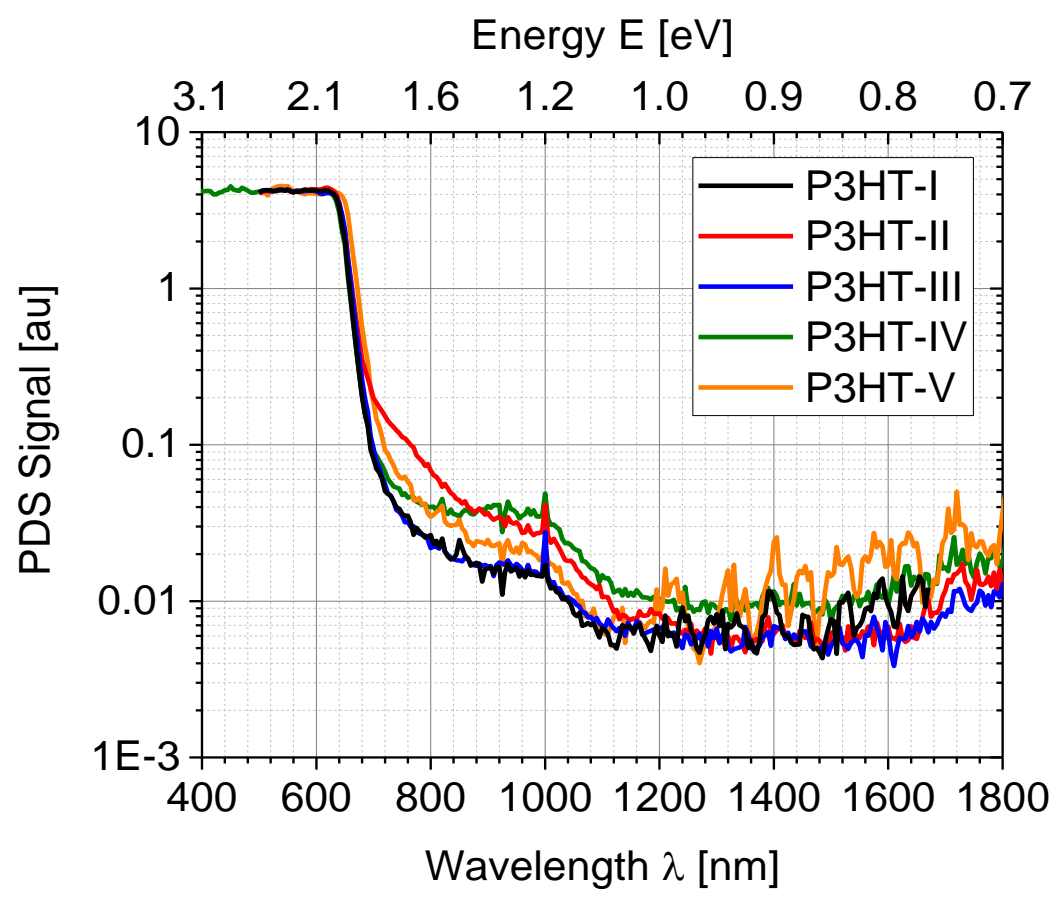

Figure 5: Results of the photothermal deflection spectroscopy measurement on pristine P3HT films. All of them show some signature of doping, visible by the peak around $1000 \mathrm{~nm}$.

\subsection{Electron spin resonance spectroscopy}

Electron spin resonance is a useful method for determining radical concentrations in the material under investigation. In this study, radicals might originate from defects at the chain capping groups, some structural defects (e.g., stabilized tri(hetaryl)amine type radicals) or certain impurities possibly stemming from the synthesis and insufficient purification. Alternatively, radicals can belong to the polymer polaronic state formed as a result of the material oxidation (oxidative doping) while handling it in air. The concentrations of persistent radical species for the P3HT-batches was estimated using ESR spectroscopy (Table 6) following previously reported procedures ${ }^{34,65,81,82}$. We did not find any correlation with the molar masses of the polymer samples, which would be a reasonable expectation if the radicals are mostly induced by defected chain capping groups. The obtained radical concentrations could also not be related with the findings from the ICP-OES measurements (Table 5), as P3HT-II generally showed relatively small levels of trace metals, but exhibits the highest radical concentration by ESR. However, some correlation could be found when comparing radical concentrations with PDS data: here P3HT-II showed the highest radical concentration in ESR, and also exhibited the strongest absorption between 700 $900 \mathrm{~nm}$ in the sub-bandgap region of the PDS spectrum. On the other hand, P3HT-III exhibited not only the lowest sub-bandgap absorption, but also showed the lowest radical concentration obtained via ESR. However, the correlation does not hold very well for the other batches, e.g. P3HT-I, exhibiting the lowest concentration of polarons as by PDS (like P3HT-III), had a relatively high radical concentration. These observations suggest that radical species identified in different samples of P3HT apparently have different origins.

Finally, it should be emphasized that concentration of radical species in all investigated P3HT samples is relatively low and should not impair the efficiency of the photovoltaic devices based on 
these materials as per previous findings ${ }^{65}$. The results of other characterization methods applied to the P3HT batches are displayed in the Supplementary Information, sections 5-8.

Table 6: Experimental results of the ESR measurements on the pristine P3HT films.

\begin{tabular}{ll}
\hline P3HT Batch & Concentration of the radicals (spin/r.u.) \\
\hline P3HT-I & $7.94 \mathrm{E}-6$ \\
\hline P3HT-II & $3.98 \mathrm{E}-5$ \\
\hline P3HT-III & $1.45 \mathrm{E}-6$ \\
\hline P3HT-IV & $4.82 \mathrm{E}-6$ \\
\hline P3HT-V & $3.13 \mathrm{E}-6$ \\
\hline
\end{tabular}

\subsection{Results of controlled aging}

\subsubsection{ISOS-L2 Degradation}

\subsubsection{Performance over time versus P3HT batches}

The ISOS-L2 protocol provides an efficient way of accelerated testing of lifetimes. Stress factors like heat (here $55^{\circ} \mathrm{C}$ in the shadow) and light (including UV-light) reveal operational weaknesses of photovoltaic devices. Due to space constraints here only the power conversion efficiency (PCE) over time curves are being displayed; see section 3.5.1.4, and the Supporting Information, section 9 , for the time development of the other photovoltaic parameters.

Considering the characterization data from above, it might be expected that P3HT-I (for metal contamination) and P3HT-II batches (for radical concentration and sub-bandgap absorption) would lead to the fastest decay in performance. However, specifically these two batches yielded the best values for stability. Similarly, if we consider the extreme cases of the molecular properties, P3HT-III representing one of the most highly ordered, and P3HT-IV representing the least ordered among all, we can find a layer stack (TEIC) in which both perform similarly well and better than all others. These results - and the fact that there was no agreement among the different sets of devices originating from different cell producers concerning which P3HT batches lead to slower or faster degradation, makes correlating the lifetime data and the P3HT properties difficult.

The performance decay for the different cell producers, respectively their layer stacks applied, are shown in Figure 6, while the corresponding ageing parameters based on various fit functions are summarized in Table 7. In order to check whether P3HT-batches do yield similar decay curves in different layer stacks, the ageing data is replotted with respect to the materials itself (Figure 7). However, no clear correlation is found between P3HT-batch and ageing slopes, thus the decay slopes generally seem to depend more on the layer stack (i.e., cell producer) than on the actual P3HT-batch used.

A more consistent behavior was found for the rather stable (but sometimes at lower performance) operation of P3HT-I and P3HT-V, which seemed to degrade generally faster (smaller lifetime) than the other batches. Unfortunately, this behavior could not be related to any P3HT property, as the latter batch had no distinct properties under all of the characterization methods reported above. 
It is interesting to note that cell producers who provided their own active layer material, obtained the most stable operation with exactly these materials. Thus, we may conclude here that experience with the material system seems to play a more dominant role in obtaining stable devices than the actual choice of P3HT-batch.

The most consistent ageing behavior was found for the devices made by TEIC, which always showed a bi-exponential decay function under ISOS-L2. Furthermore, TEIC cells demonstrated that with a sufficiently good encapsulation it is also possible to reach a relatively high lifetime with conventional architecture. The outstandingly highest device stability was reached by CEA with the self-provided P3HT batch (P3HT-I), leading to similar LEY values as reported in the literature $^{7}$. It is interesting to note that also poorly encapsulated inverted devices failed faster than the conventional devices, which was most pronounced in the case of the UTV and ICN2 devices. This observation suggests the need to re-assess the inverted layer stacks concerning their inherent intrinsic stability problems.

The low stability observed for the UTV devices might be connected with the encapsulant Surlyn, as its glass transition temperature $\left(T_{g}\right)$ is below $60^{\circ} \mathrm{C}$. Though the heating in the chamber was set to $55^{\circ} \mathrm{C}$ in the shadow, the cell temperature can be expected to be considerably higher owing to direct exposure to full light spectrum and associated heating effects. As diffusivity suddenly increases above $T_{g}$, especially oxygen ingress might have happened at an increased rate. This assumption is supported by the fact that the Surlyn encapsulation layer is thicker than the epoxy layers used and thus can lead to higher ingression rates and then serve as a larger reservoir for oxygen $^{83,84}$. 

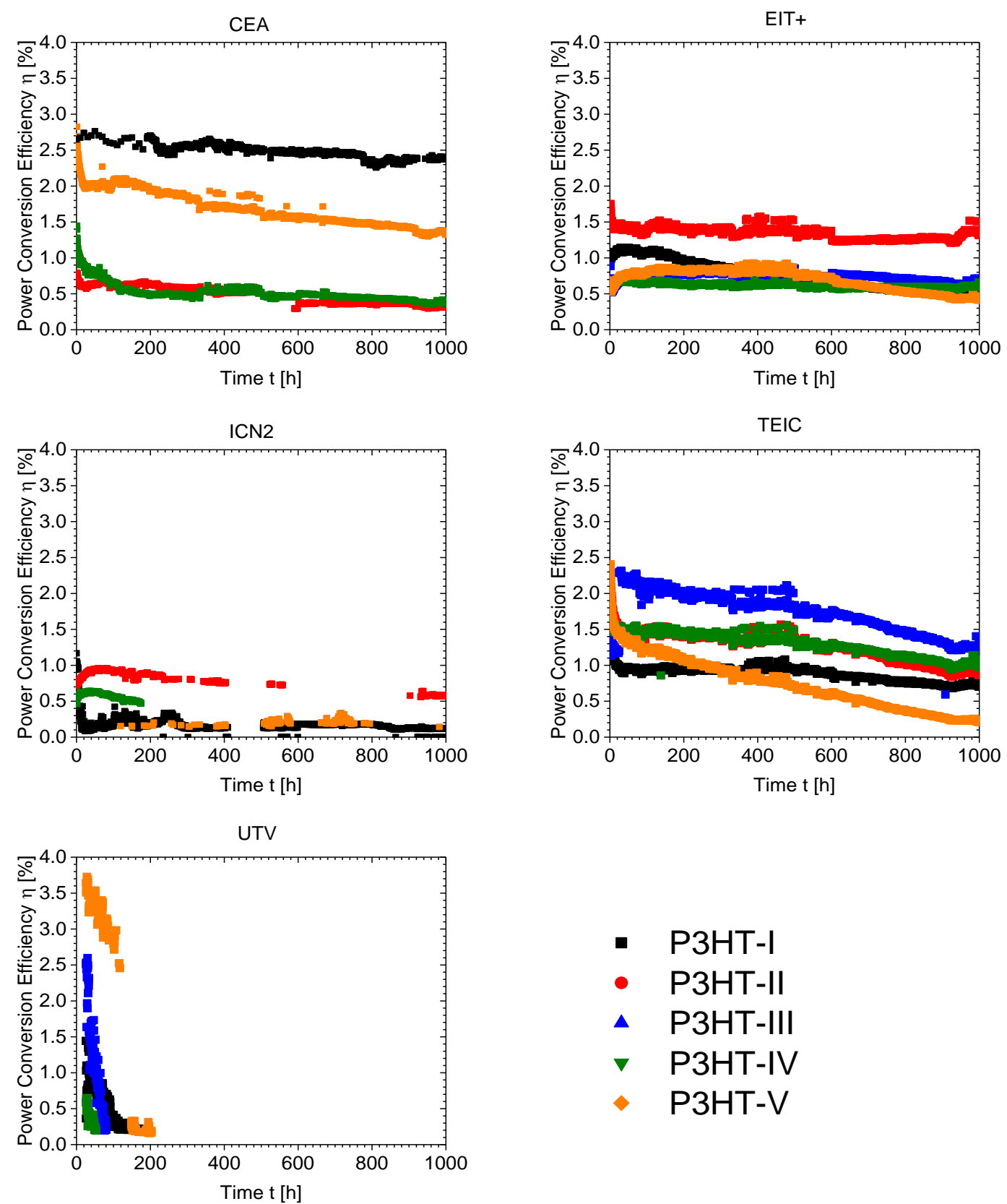

- P3HT-I

- P3HT-II

- P3HT-III

$\checkmark$ P3HT-IV

- P3HT-V

Figure 6: Aging curves for organic solar cells of the different manufacturers (indicated in the title of each panel) from the ISOS-L2 measurements performed at CEEC Jena, with different P3HT-batches.

\subsubsection{Performance over time versus Cell Producer}

In Figure 7 it is clearly visible that the cell producer, i.e. the device layout, is more dominating the aging behavior than the P3HT. The same P3HT batch exhibits strongly varying aging behavior for the different producers, like P3HT-I which shows a nearly linear decay for EIT+, though showing a bi-exponential decay behavior for TEIC and a more or less constant operation in case of CEA. The burn-in behavior for the individual P3HTs is independent of the P3HT batch 
used as can be seen from the aging curves of each producer. Hence the degradation of the interfaces and interfacial and electrode materials (partially influenced by the sealing) have a larger impact, than the variation of polymer properties found in the P3HTs used for the experiment.
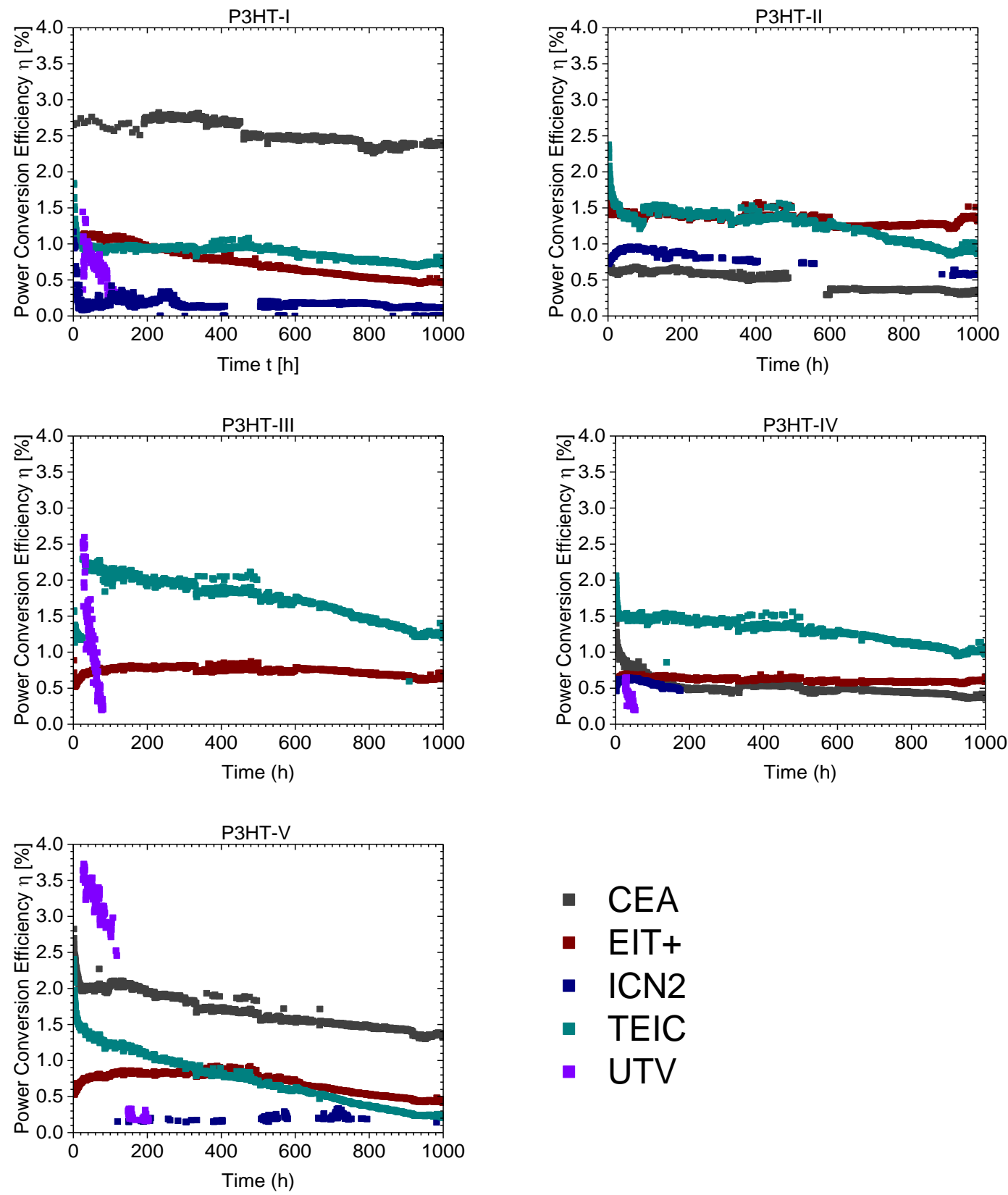

- CEA

- EIT+

- ICN2

- TEIC

- UTV

Figure 7: ISOS-L2 aging data plotted for individual P3HT-batches (indicated in the title of each panel) for solar cell producer, respectively, their device layout.

\subsubsection{Evaluation of Lifetime Energy Yield (LEY)}

CEA and EIT+ demonstrated record LEYs of $\sim 53 \mathrm{kWh} / \mathrm{m}^{2}$ and $20 \mathrm{kWh} / \mathrm{m}^{2}$ based on devices built with their self-provided material P3HT-I and P3HT-II, respectively (see Tables 2, 7). This fact is 
unexpected, as P3HT-II exhibits considerably different material properties than P3HT-I, and the low performance in EIT+ devices cannot be explained. Among the other materials, maximum LEY values of ca. $10 \mathrm{kWh} / \mathrm{m}^{2}$ were reached, for P3HT-III by TEIC, for P3HT-IV by EIT+ and for P3HT-V by ICN2. In general, the aging characteristics obtained by one producer were not identical for the different materials used. In case of P3HT-I based solar cells built by CEA the first $200 \mathrm{~h}$ are missing due to some contact problem observed only later. As no burn-in was observed, it may be highly probable that this device completed burn-in before reconnection occurred. From the best stabilities obtained for the record devices of CEA and EIT+ some further conclusion concerning the hole extraction layer can be made: CEA used inverted architecture with PEDOT:PSS, while EIT+ used $\mathrm{MoO}_{3}$ for hole extraction. Thus, at least PEDOT:PSS cannot be claimed responsible for yielding insufficient OPV stability. For completeness it should be mentioned that the total device area is not a relevant parameter for stability, as these two cell producers delivered the largest and the (nearly) smallest solar cell areas. Further data of LEY analysis of L2 degradation experiments can be found in the Supplementary Information, section 13.

\subsubsection{Remarkable exceptions}

The highest stability in terms of lifetime was generally shown by P3HT-I cells. A remarkable exception was observed for P3HT-I cells provided by ICN2: while devices generally suffered from insufficient encapsulation, this device basically showed an "eternal" lifetime (no slope), however, at a very low performance level (<0.2\% PCE). We decided to cut the lifetime at 10000 hours, as further extrapolation to longer lifetimes is not really supported by an about 1000 hours lasting ageing experiment.

\subsubsection{Photovoltaic parameters}

In the following the photovoltaic parameters of L2-aged devices are briefly reviewed. All solar cells showed a short and very small burn-in of the open-circuit voltage under L2 conditions, which can be seen in Figures $S 12, S 15, S 18, S 21$ and $S 24$. This can be explained either by an increase in energetic disorder, which is rather unlikely due to the crystalline nature of $\mathrm{P} 3 \mathrm{HT}^{25}$, or more likely by a slight increase in crystallinity in the material due to light and heat stress and thereby a change of the energetic landscape along the donor/ acceptor interface ${ }^{85}$.

Except for a few devices, all showed the rather common burn-in with a bi-exponential decay behavior of the short circuit current density for P3HT, see Figures S13, S16, S19, S22 and S25. This is a well-known feature for P3HT:PCBM solar cells and an important contributor to this decay is the increase in phase separation between P3HT and PCBM, which leads to a reduction of interfacial area where excitons could be separated and thereby to a reduction in photocurrent generated $^{6,86}$. Notable exceptions are all of the devices by EIT+, see Figure S16, which initially show an increase in photocurrent followed by a nearly linear decay. This increase in photocurrent could indicate further annealing under light and elevated temperature. Another option for this initial increase might also be the necessity for photo-activation of the ETL material ${ }^{87}$. Interestingly, the most stable device of $\mathrm{CEA}^{86}$ processed with P3HT-I was limited by a slowly decaying short circuit current, while the other photovoltaic parameters were virtually constant. 
Table 7: Results of curve fitting of the performance decay over time. Given are the fit function, the burn-in time $T_{S}$, efficiency after burn-in $E_{S}$, operational lifetime $T_{S, 80}\left(\right.$ or $\left.T_{80}\right)$ and efficiency at the end of nominal lifetime $E_{S, 80}\left(\right.$ or E $\left.E_{80}\right)$. Finally the calculated lifetime energy yields (LEYs) for the L2 aged solar cells are given. See S59-S80 for the respective fits. (* - lifetime from data is infinite and thus was limited to the tenfold stressing time, \# denotes catastrophic failure)

\begin{tabular}{|c|c|c|c|c|c|c|c|}
\hline Manufacturer & $\begin{array}{l}\text { P3HT } \\
\text { Batch }\end{array}$ & $\begin{array}{l}\text { Fit } \\
\text { function }\end{array}$ & $\begin{array}{l}\mathrm{E}_{\mathrm{S}} \\
(\%)\end{array}$ & $\begin{array}{l}\mathrm{T}_{\mathrm{S}} \\
\text { (h) }\end{array}$ & $\begin{array}{l}E_{S, 80} \text { or } E_{80} \\
(\%)\end{array}$ & $\begin{array}{l}\mathrm{T}_{\mathrm{S}, 80} \text { or } \mathrm{T}_{80} \\
\text { (h) }\end{array}$ & $\begin{array}{l}\mathrm{LEY} \\
\left(\mathrm{kWh} / \mathrm{m}^{2}\right)\end{array}$ \\
\hline \multirow[t]{5}{*}{ CEA } & P3HT-I & $\operatorname{Exp}$ & - & - & 2.32 & 2241 & 52.9 \\
\hline & P3HT-II & Lin & - & - & 0.55 & 355 & 2.16 \\
\hline & P3HT-III & & & & & & \\
\hline & P3HT-IV & BiExp & 0.56 & 172 & 0.44 & 826 & 4.44 \\
\hline & P3HT-V & BiExp & 1.84 & 24 & 1.47 & 509 & 9.56 \\
\hline \multirow[t]{5}{*}{ EIT+ } & P3HT-I & Exp & - & - & 0.93 & 229 & 2.39 \\
\hline & P3HT-II & BiExp & 1.44 & 16 & 1.15 & 1594 & 20.5 \\
\hline & P3HT-III & Lin & - & - & 0.65 & 1088 & 8.01 \\
\hline & P3HT-IV & Lin & - & - & 0.53 & 1547 & 9.18 \\
\hline & P3HT-V & LogLin & 0.85 & 180 & 0.56 & 784 & 5.81 \\
\hline \multirow[t]{5}{*}{ ICN2 } & P3HT-I & BiExp & 0.22 & 35.9 & 0.17 & $10000^{*}$ & 14.6 \\
\hline & P3HT-II & Exp & - & - & 0.76 & 458 & 3.9 \\
\hline & P3HT-III & - & - & - & - & - & - \\
\hline & P3HT-IV & Exp & - & - & 0.55 & $114^{\#}$ & $0.70^{\#}$ \\
\hline & P3HT-V & BiExp & 0.15 & 437 & 0.12 & 7248 & 9.83 \\
\hline \multirow[t]{5}{*}{ TEIC } & P3HT-I & BiExp & 1.02 & 21 & 0.81 & 733 & 6.71 \\
\hline & P3HT-II & BiExp & 1.6 & 24 & 1.27 & 454 & 6.56 \\
\hline & P3HT-III & Lin & - & - & 1.79 & 458 & 9.23 \\
\hline & P3HT-IV & BiExp & 1.47 & 11 & 1.26 & 546 & 7.71 \\
\hline & P3HT-V & BiExp & 1.46 & 22 & 1.16 & 155 & 2.11 \\
\hline \multirow[t]{5}{*}{ UTV } & P3HT-I & Lin & - & - & 0.91 & $34^{\#}$ & 0.35 \\
\hline & P3HT-II & - & - & - & - & - & 0 \\
\hline & P3HT-III & Lin & - & - & 2.43 & $17^{\#}$ & 0.45 \\
\hline & P3HT-IV & Lin & - & - & 0.67 & $14^{\#}$ & 0.1 \\
\hline & P3HT-V & Lin & - & - & 3.62 & $40^{\#}$ & 1.61 \\
\hline
\end{tabular}


Finally, the fill factor showed some very interesting differences for some cases even among cells of one manufacturer. For CEA L2, Figure S14, P3HT-I showed a constant FF for the entire experiment. This might be connected to its high crystallinity and no further annealing occurring during the aging process, as well as no formation of major barriers between the different interface layers. P3HT-IV and P3HT-V, in contrast, showed a burn-in followed by a linear decay. A reason for this might be the formation of barrier layer for extraction, doping induced space-charge or an increase in disorder in the active layer material. For EIT+, see Figure S17, there was nearly an identical behavior in fill factor for all the different materials, which suggests that the behavior of the cells was fully determined by the device layout and the large series resistance. Interestingly, the fill factor of $30 \%$ constitutes the limiting parameter for the performance of the most stable device, processed from P3HT-II. There was a fast exponential burn-in followed by a nearly linear weak decay afterwards. There is a slight difference in the slope of the linear part of the decay curve, which might be due to differences in the P3HT-batches. ICN2 showed rather low fill factors already from the start, see Figure S20, but P3HT-II showed first an increase in FF followed by a linear decay. This might be related to an annealing process of the cell, which induces more crystallinity, followed by ingress of oxygen and trap formation ${ }^{26}$. However, the value of $25 \%$ found for several devices is due to a shunting problem. TEIC cells, see Figure S23, showed, with the exception of P3HT-I, a nearly constant linear decay of the fill factor. This is most likely connected with the oxidation of the low work function metal electrodes of this conventional device architecture.

The most durable solar cell exhibited - as expected - an inverted architecture, and reached a LEY above $52 \mathrm{kWh} / \mathrm{m}^{2}$. Due to avoiding low work-function metals, inverted architectures are less susceptible to moisture and oxygen ingress, which can corrode the low work function metal rapidly. The major issues found with proper encapsulation and resulting electrode corrosion as a reason for early failure, pronounce again the importance of a) a good sealing and b) in an inverted architecture to be more resilient against any breach of encapsulation.

We found that with a proper encapsulation even conventional devices can be rather stable, which can be seen in the LEYs achieved by the TEIC devices. On the other hand, as stated earlier, with a suboptimal encapsulation not even an inverted architecture can avoid drastic failures, as can be seen in the cases of ICN2 and UTV cells.

\subsubsection{Usefulness of $L 2$ for stability experiments}

The ISOS-L2 protocol allows determining the photostability of devices in an accelerated way. In combination with ISOS-D2 characterization the effect of the elevated temperature can be deconvoluted in order to learn about the pure light stability. Hence the performance decay observed in L2 should be expected to be more than for O1 and D2, assuming a perfect encapsulation and a sufficiently long measurement period. L2 ageing might also allow for drawing conclusions about the lifetime of a device under realistic operation in the field (outdoors). It is assumed that a lifetime of 1000-2000 h under L2 roughly corresponds to a

lifetime of 1 year in the field under stable sealing 5 . Thus the most stable devices of this study correspond to about 1-5 years operational stability in the field. 


\subsubsection{External Quantum Efficiency for L2-Ageing}

Besides the pure stability and performance information, external quantum efficiency (EQE) measurements can yield additional information. In accordance with its high crystallinity, solar cells processed with P3HT-I commonly have an absorption onset towards longer wavelengths than those of the other P3HT batches (see Figure 8). In case of the inverted device structure (here $\mathrm{CEA}$, EIT+, and ICN2) the spectral response remains stable in its qualitative characteristics. However, for the only conventional device architecture (TEIC) an interesting effect is observed: upon aging the regions exhibiting highest absorption by P3HT-I show lower charge extraction for the L2 aged device. This may refer to an unfavorable vertical material gradient that inhibits charge extraction from a certain region of the device, where a higher P3HT-I concentration is present. This could be due to a build-up of a space charge region within the active layer, where a higher concentration of P3HT-I is present ${ }^{88}$. However, this effect takes place already early during aging, specifically during the burn-in process, and thereafter the performance remains fairly stable - in fact this was the most stable of all devices processed in conventional architecture. Thus this type of burn-in degradation might be best related to the relatively high number of metal impurities, as well as radical concentrations, as found by ICP-OES and ESR. However, in unprocessed pristine P3HT-I fairly low polaron densities (PDS) were found, indicating that only the combination of light and metal impurities may play a dominant role here for the generation of space charge. As the overall behavior of all devices cast from this P3HT-I is relatively stable (as seen by the long lifetimes), the observed losses should in all cases be related to space charge built up due to inherent impurities present in the material from the beginning. Thus, we may speculate that the same P3HT without the space charge would yield much higher performances for longer times. Further data of EQE measurements related to L2 degradation experiments can be found in the Supplementary Information, section 12. 


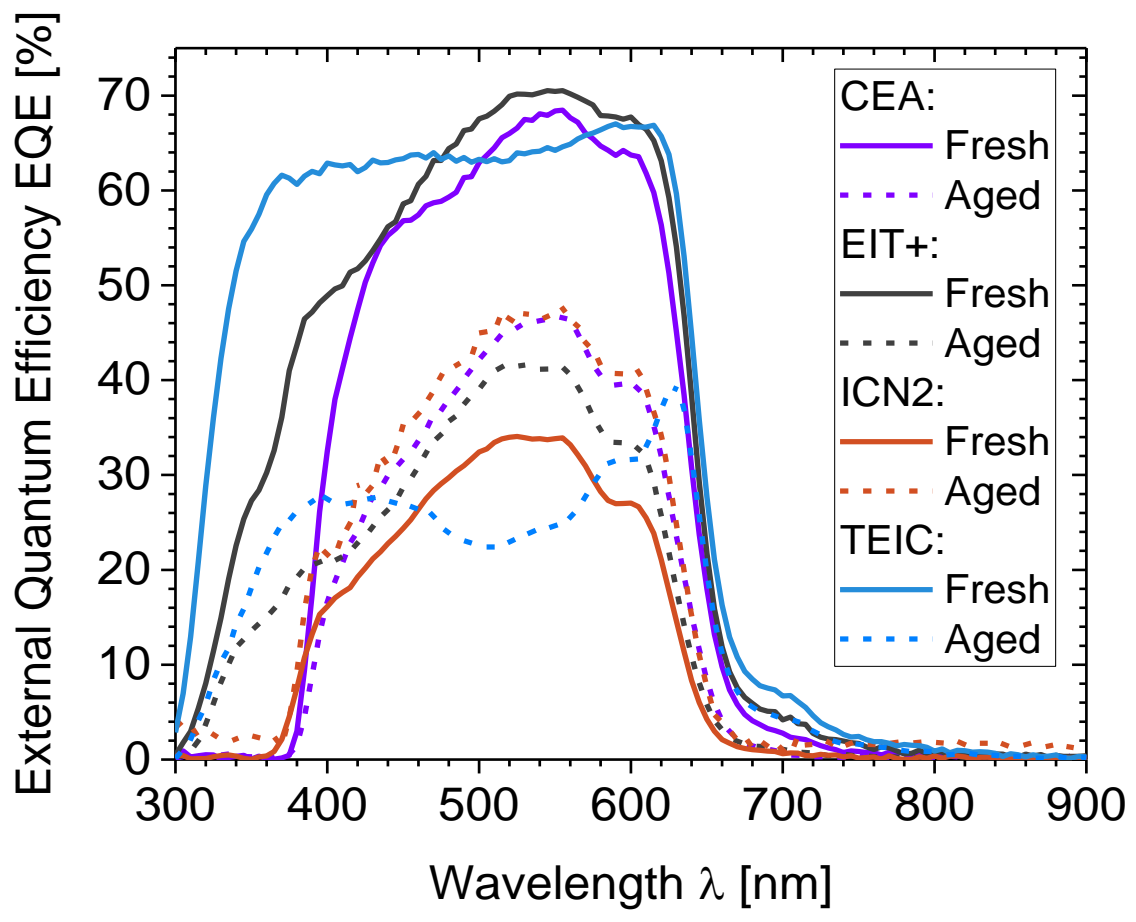

Figure 8: EQE spectra for P3HT-I solar cells from different manufacturers before and after L2 aging.

Upon comparison of the EQE-data with the ageing data of the photocurrent from ISOS-L2 we can find a severe deviation for the CEA-P3HT-I sample between the photocurrent measured under the solar simulator $\left(\sim 8 \mathrm{~mA} / \mathrm{cm}^{2}\right)$ and the one from integration of the EQE-curve and multiplication with a hypothetic AM 1.5 spectrum: the EQE-curve delivers only $5.72 \mathrm{~mA} / \mathrm{cm}^{2}$. This deviation could be assigned to trap-assisted charge recombination or an extraction barrier in the low-light level case, which can be overcome by trap-filling for higher excitation densities. A similar effect was recently observed in P3HT-PCBM cells ${ }^{89}$. It is interesting to note that already in the beginning of the experiment, light bias yielded a gain in photocurrent for the same device, see Figure 9. Unfortunately, no EQE with bias measurements were performed after the L2ageing. 


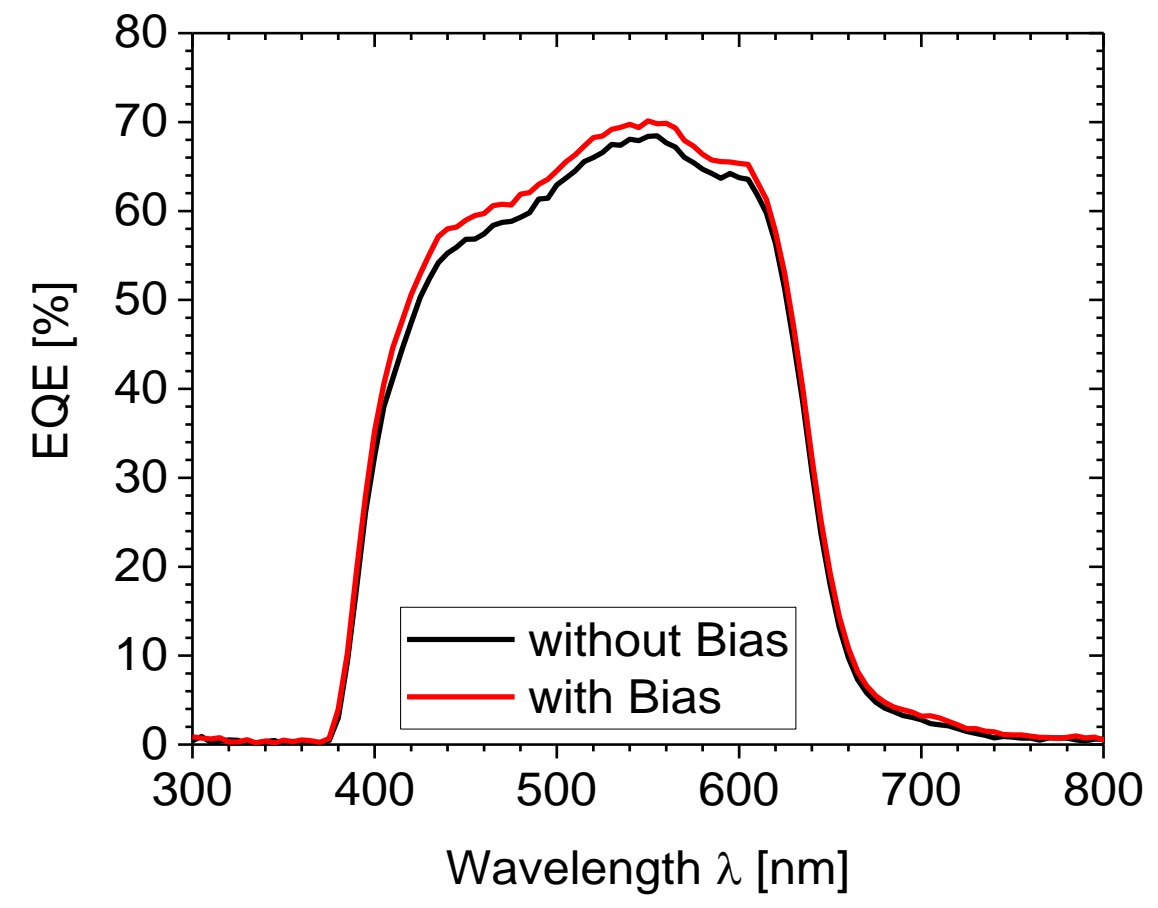

Figure 9: EQE measurement with and without bias light for CEA-P3HT-I cell before L2 degradation determined at CEEC Jena.

\subsubsection{ISOS-D2 Degradation}

In contrast to our expectation, the photovoltaic devices suffered on average more degradation under dark storage at elevated temperatures (ISOS-D2), seen in Figure 10, than under accelerated laboratory weathering (ISOS-L2). Notable exceptions were found only for EIT+ and TEIC devices, which showed higher performances than under L2. In case of the EIT+ solar cells drastic device failure is visible for P3HT-II, indicating breakage of the sealing. This hints that for these configurations the thermal stability is much more relevant than the light stability. However, even for the case presented here, where the L2 ageing took place at slightly lower temperatures of $55^{\circ} \mathrm{C}$ in the shadow, similar temperatures are to be expected within the devices for L2, as the light absorption itself must inevitably lead to heating. Further this means that EIT+ cells show a good thermal stability, while their photo-stability is lower than those of the other cells. This might be connected to light-induced doping effects arising from the $\mathrm{MoO}_{3}$ hole transport layer. On the other hand, devices produced by UTV and ICN2 exhibited similarly low stability as under L2, indicating degradation mechanisms to be independent of light. In general, it should be noted that insufficient sealing effects may have played a more important role under D2 than under L2 aging, as for $\mathrm{D} 2$ not the innermost devices were chosen, but rather the best performing ones.

An interesting deviation appeared for the TEIC solar cells, which did not show a fast burn-in, but rather a linear long-term decay. This hints to a light induced rather than a thermally induced process for the burn-in, independent of the P3HT batch used. Furthermore, the CEA cells degraded severely, independent of the $\mathrm{P} 3 \mathrm{HT}$ batch, indicating a thermally driven process that might be prevented (at least for the most stable P3HT-I batch) under illumination. Finally, it 
should be noted that the highest performing devices (yielding also highest hypothetical LEYs) provided by EIT+ were obtained with the already identified superior P3HT-batches I and II. Further data of D2 degradation experiments can be found in the Supplementary Information, section 10.
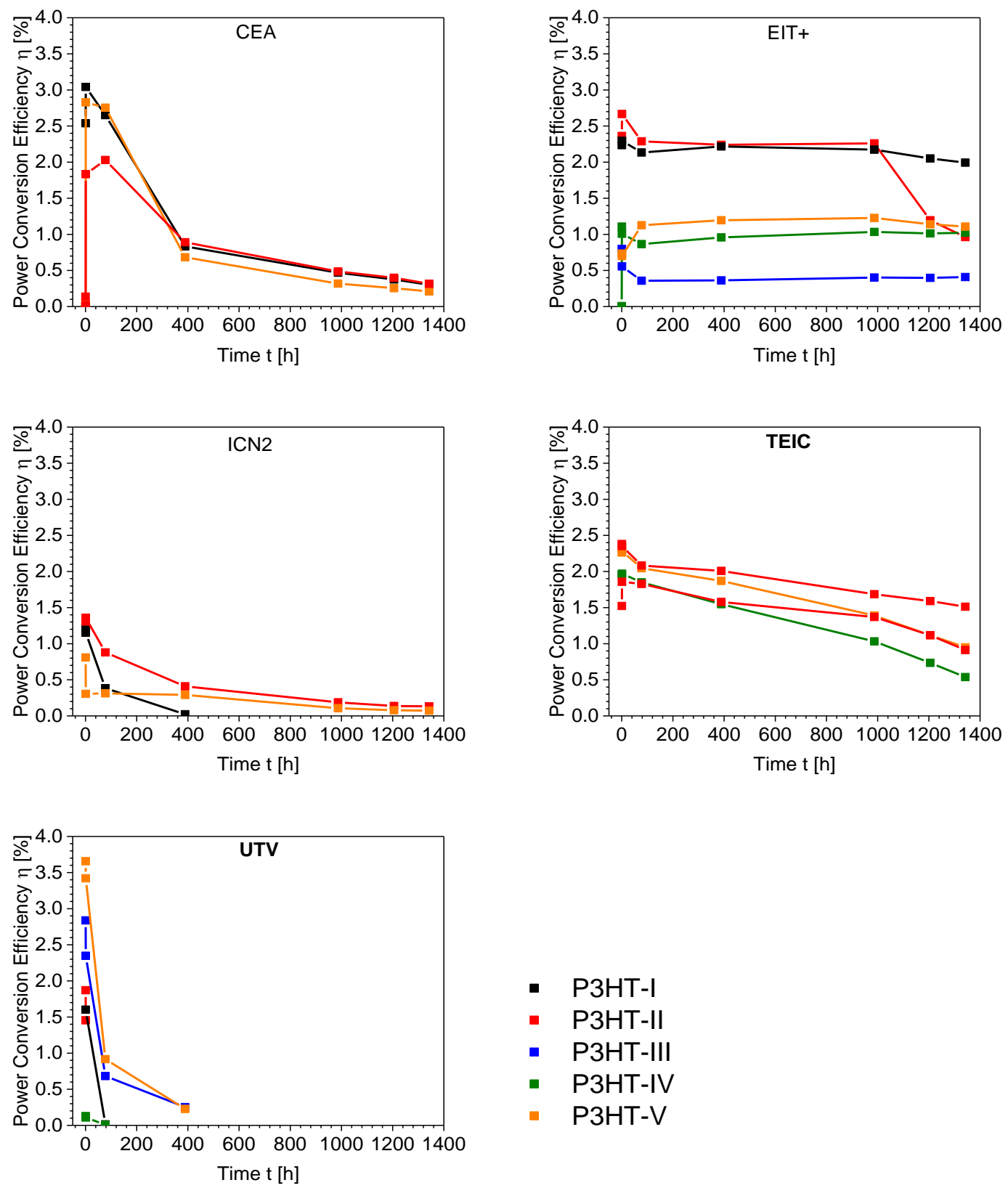

- P3HT-I

- P3HT-II

- P3HT-III

- P3HT-IV

- P3HT-V

Figure 10: Aging data from ISOS-D2 experiment done by Solliance in Eindhoven.

\subsubsection{ISOS-O1 Degradation}

The observations made for dark ageing under elevated temperatures could in part also be found for ISOS-O1, see Figure 11. As a matter of fact, the EIT+ devices outperformed in terms of stability for this ageing condition those aged under L2. Again, the identified superior P3HTbatches, namely I and II, yielded the best performance over time here. Noteworthy are the 
devices provided by TEIC: although they showed considerable degradation following exponential decays, there was no indication of drastic failure. This confirms the superiority of the encapsulation used in this case over the other device layouts. In case of the remaining cell producers, drastic failure was observed in all cases, independent of the P3HT batch used. Hence the conditions even under this modified outdoor ageing seemed to be dominated by environmental impacts such as water or oxygen ingress. Interestingly, ICN2 solar cells based on the P3HT-batches I and II also outperformed the other batches, confirming their superiority. However, such exceptions were not observed in case of CEA, TEIC and UTV, where rather a material independent degradation was found. Further data of $\mathrm{O} 2$ degradation experiments can be found in the Supplementary Information, section 11.
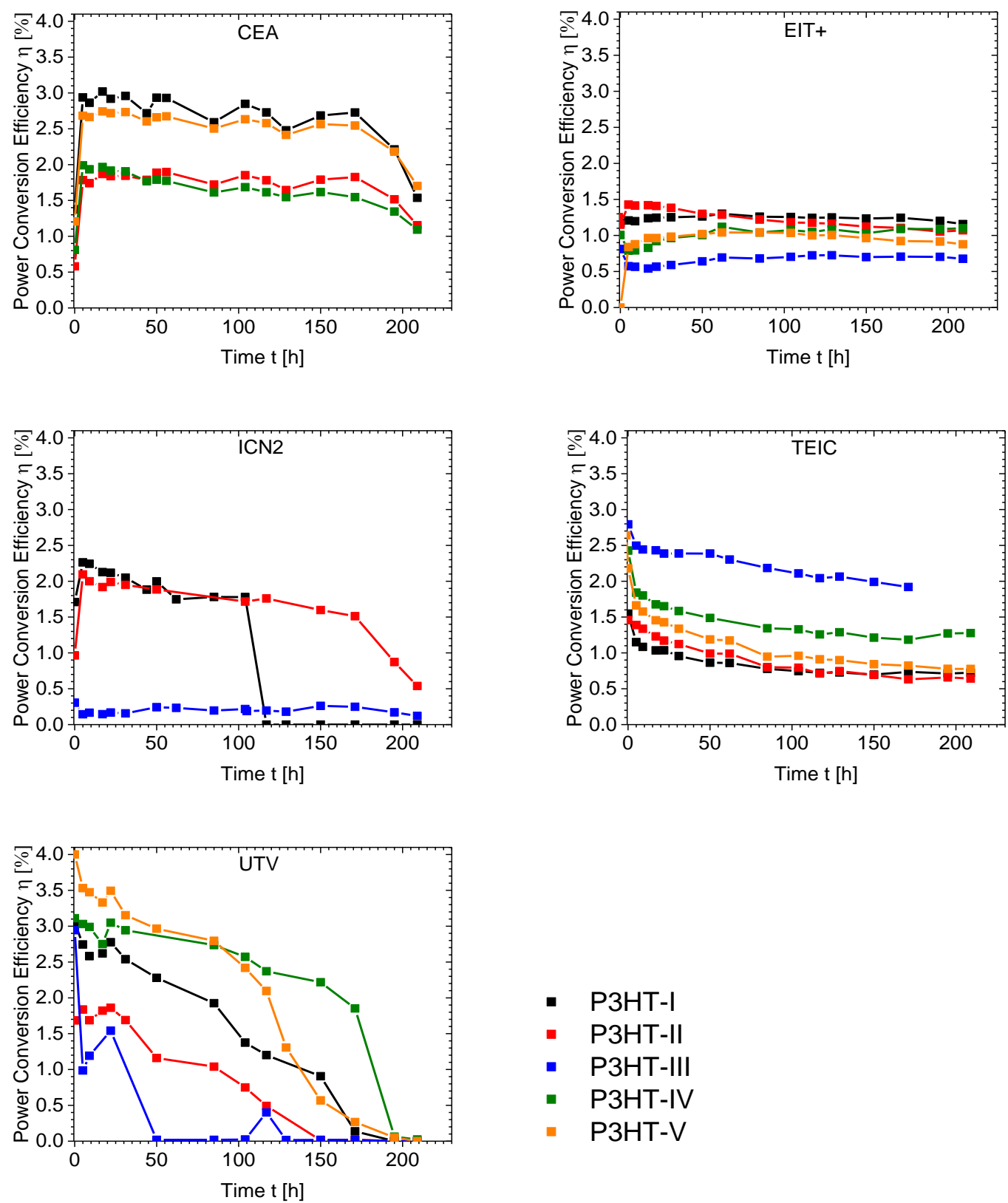

- P3HT-I

- P3HT-II

- P3HT-III

- P3HT-IV

- P3HT-V

Figure 11: Aging data for ISOS-O1 measurements performed at BGU in Sede Boqer in Israel. 


\subsection{Paios Results}

It has been shown that by a combination of various transient and impedance experiments, and a complementary data analysis, certain aging mechanisms can be revealed by their specific signatures ${ }^{74,73}$. For example, an overshoot observed in the transient photocurrent is a trace of charge accumulation (space charge), which can occur due to trapping or an energetic barrier for charge extraction. The impedance signal of the two cases (trapping or energetic barrier), however, looks different, and therefore allows distinguishing between the two mechanisms. Another example is charging of the active layer (doping), which can be determined by combining impedance and CELIV measurements.

Unfortunately, no systematic behavior for devices of the same producer or using the same P3HT batch could be found. We identified two main reasons for this: i) the low reproducibility in cells obtained make a cell-to-cell comparison erroneous, ii) the significantly differing stack architectures and sample geometries turn out to have an enormous impact on the initial cell performances and their stability. Yet, several conclusions can be drawn from this supplementary experiment.

In order to perform transient measurements small devices with a low RC time constant are required. This is, however, not only a necessary condition for analytic models to be valid ${ }^{90}$, but also impacts any electrical measurement on the device. Large resistance values have been found in all cells produced by EIT+ using the Osilla layout, which is mainly due to the un-metallized ITO contact. A series resistance of $200 \mathrm{Ohm}$ already affects the steady-state performance of the device and should therefore be avoided. This observation nicely agrees with the observed low fill factors. The UTV layout, on the other hand, showed negligible contact resistances.

We further found shunting by leakage currents to be a major failure mechanism. Here devices by UTV, ICN2, and EIT+ were most sensitive, and the O1-aged devices showed more severe shunting than L2-aged ones. The underlying mechanisms for this behavior are however not understood. 
Another important conclusion from the Paios measurements is that encapsulation failure, leading to the lateral in-diffusion of oxygen and water vapor, can superimpose to the degradation process of the active layer and will induce additional pathways for degradation which should be prevented. The inhomogeneous oxidation of the metal electrode from the sample edges forms an insulating oxide layer hampering charge extraction. A prominent signature of this process is a strong overshoot in the transient photocurrent signal ${ }^{74}$.
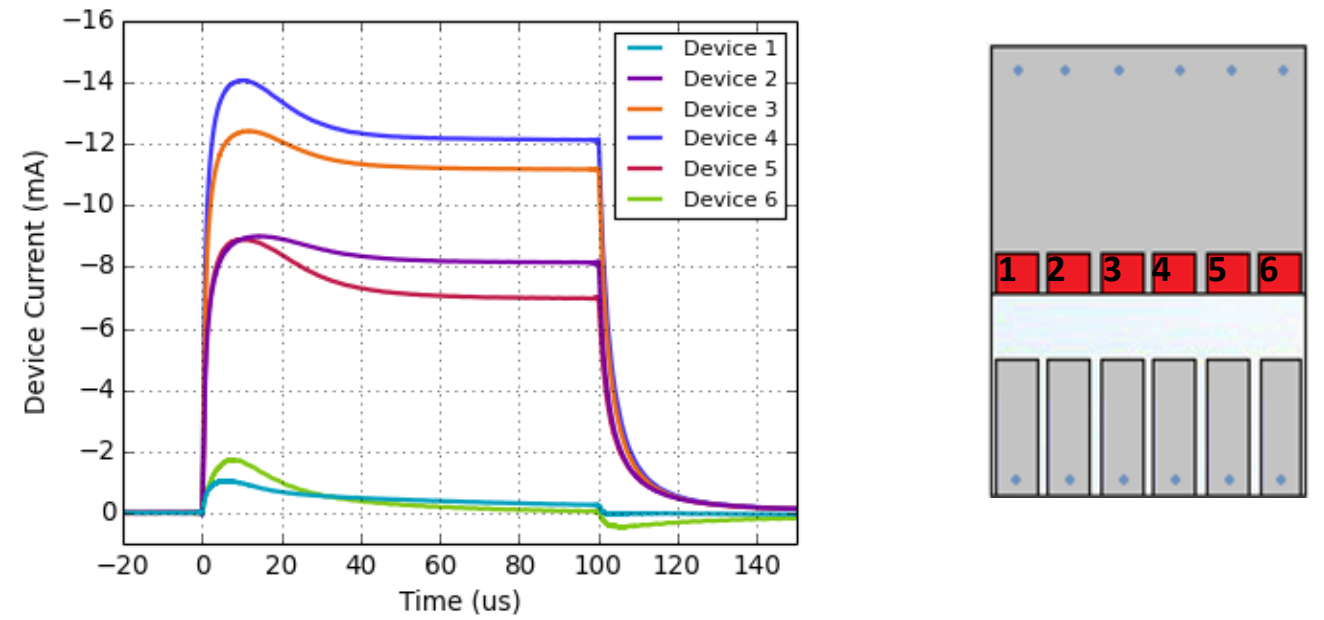

Figure 12: Transient photocurrent results for TEIC solar cells after aging.

Figure 12 shows an example of a TEIC sample, where the outer devices show more severe degradation due to the failure of the encapsulation adhesive. The further to the edge the cells were, the weaker was the measured signal, which shows there was ingress of oxygen and moisture through the encapsulation. This effect was found more pronounced in cells aged under L2 at CEEC Jena than under O1 in the Negev. We therefore speculate that it is driven by the oxygen diffusion, supported by elevated temperatures under L 2 conditions ${ }^{91}$.

\section{Discussion}

Two P3HT-batches showed in several cases - however, not consistently over all cell producers exceptional stability: P3HT-I and P3HT-II. However, these two batches exhibit significantly different materials properties:

P3HT-I, yielding the exceptionally high LEY of $53 \mathrm{kWh} / \mathrm{m}^{2}$ under accelerated ISOS-L2 ageing, is distinguished from the other batches by its high crystallinity; however, P3HT-III showed in the optical characterization the strongest aggregate absorption ${ }^{92,93}$. Furthermore, P3HT-III remained similarly inconspicuous concerning sub-bandgap absorption like P3HT-I. However, except for TEIC cells based on P3HT-III under outdoor degradation (ISOS-O1), this P3HT-batch rather underperformed in all stress tests compared to the other cell producers. The fact that P3HT-III exhibited the lowest radical and trace metal concentrations of all batches, seems to make this material property rather insignificant concerning its impact on yielding stable organic solar cells. Thus, the only remaining material parameter that could be blamed for the low stability can be the exceptionally low molar mass of this batch, roughly three times lower than all others. Microscopically, the low molar mass might be connected to an unfavorable phase behavior; either unsuitable crystallization leading to phase separation and thus loss in charge generation and diode characteristics, or vertical phase segregation reducing the fill factor and potentially the 
open-circuit voltage as well. It is known that lower molar mass P3HT samples lead to high crystallinity, while higher molar mass result in different crystallites due to chain backfolding ${ }^{51,94,95}$. Besides the fact that several devices based on P3HT-III were missing out from the studies, this batch gave usually the lowest open-circuit voltages, except for the UTV devices where it yielded the highest ones. The difference that UTV devices showed with respect to all others must be connected to its electron extraction layer, which consisted of PEIE. This seems to make a big difference, potentially preventing interfacial recombination otherwise leading to a reduction of the quasi-Fermi level splitting. Getting back to P3HT-I and its properties, we may take the sub-bandgap absorption as the only remaining factor to take into account. Thus, low intrinsic doping levels and well-ordered domains, while keeping the molar mass large enough, seem to display a necessity for reaching long lifetimes at appreciable performances.

The second best result for lifetime energy yields was obtained with P3HT-II (by EIT+), although it exhibited rather opposite material properties than P3HT-I in all cases. However, its LEY remained below one half of that obtained by CEA with P3HT-I under ISOS-L2 conditions, clearly making this batch second choice. Part of the explanation for a LEY of $\sim 20 \mathrm{kWh} / \mathrm{m}^{2}$ thus should be assigned to the experience by EIT+ with this material, as it was (as in the case of P3HT-I and CEA) provided by this lab. This reason might be also responsible for comparable performances between P3HT-I and -II obtained by EIT+ in the other ageing tests (D2, O1). Thus it may be concluded that experience with a material system plays a major role in getting stable performances.

Unfortunately, not all cell producers could reproduce these results: in two cases (ICN2, UTV) this was not possible due to insufficient encapsulation of the devices, leading to extrinsic degradation becoming dominant. However, concerning the layers involved it might be indicated that PEIE is less suitable than $\mathrm{ZnO}$ for long-term stable electron extraction and $\mathrm{V}_{2} \mathrm{O}_{5}$ might be less stable than $\mathrm{MoO}_{3}$ and PEDOT:PSS. The most reliable sealing of samples could be demonstrated by EIT+ and TEIC, specifically for the ageing tests obtained under ISOS-D2 and ISOS-O1. This means that - at least for glass-glass sealing - also conventional devices exhibiting PEDOT:PSS layers can reach substantially high intrinsic stabilities.

The experience gained from this collaboration experiment could be summarized as follows: if cell producers are confronted with new material systems with which they have no processing experience, a longer preparation and training time before providing devices for ageing tests is required. Of course a proper sealing method and corresponding encapsulation materials are required. Furthermore, improved statistics obtained by averaging over more devices may provide more reliability in ageing characteristics. The fewer devices take part in such an ageing experiment, the higher is the risk of losing devices due to catastrophic failures, which drastically lowers the chance for finding correlations between materials or layer stack properties. Finally, the design of the ageing experiments should be such that a sufficient amount of data points (>>10) over time to enable a reliable fitting procedure, leading to a well-predictable long-term behavior.

According to the data, large lifetimes alone seem not to be an appropriate way of expressing the stability, since severe performance losses during burn-in would be disregarded. Hence we have chosen to use the determination of the lifetime energy yield (LEY), as this parameter combines lifetime and performance into one figure of merit, which expresses the usefulness of the solar 
cells in applications. This analysis is also of vital importance for solar cells with reversible degradation, for instance for perovskite-based photovoltaics ${ }^{96}$.

\section{Conclusion}

In conclusion, though the overall statistics in this experiment were challenging due to partially insufficient encapsulation and thus extrinsic degradation, some rules concerning the materials properties could be found, which can help to develop intrinsically more stable organic photovoltaic devices. In case of the semi-crystalline organic semiconductor poly(3-hexylthiophene), high crystallinity, sufficiently high molar mass and minimum intrinsic doping levels, as well as minimal disorder as found by photothermal deflection spectroscopy, are beneficial parameters contributing to stable photovoltaic operation. Interestingly, trace metal contents and radical concentrations seem to have no remarkable impact on device stability.

Furthermore, we found that the burn-in behavior of organic solar cells is mostly dependent on the layer stack. This means that part of the burn-in may stem from a) electrodes, b) transport layers, c) interfacial changes at the layer boundaries, d) differences in phase segregation of the active layer (i.e. stratification) due to different surface energies of the adjacent layers, or from e) a combination of the aforementioned factors.

Although we were able to see a slight impact of the properties of the P3HT used on the stability of the devices it did not have a dramatic effect on their stability. As the suppliers chosen for this study are widely used by different labs in the OPV community as material suppliers that means that results obtained in other studies are broadly viable in showing if a certain electrode material or transport layer material has an impact on device stability in more general terms and not only in terms of their exact combination of materials. This is especially important as P3HT still is one of the main work horses as a material in the OPV community, due to its relatively low price and wide availability.

In addition, experience with a certain material system seems to be an important parameter contributing to achieving relatively stable solar cells. Finally, the common suspect for insufficient organic solar cell stability, PEDOT:PSS, seems to perform better than its reputation, since the best devices in this comparison obtained with it in an inverted device architecture show competitive lifetime energy yields of more than $50 \mathrm{kWh} / \mathrm{m}^{2}$.

\section{Acknowledgements}

All authors are grateful for support from COST Action MP 1307, "StableNextSol". This article is based upon work from COST Action StableNextSol project MP1307, supported by COST (European Cooperation in Science and Technology). RM, TF, DF, RR and HH are grateful for financial support within the frame of "AIMS in OPV" junior research group by the BMBF, Germany. L.C. is thankful to ENEA (Ente Nazionale Energia e Ambiente) and the Italian Ministry of Foreign Affairs for a visitor post-doc fellowship to BGU. FG and MD are grateful for financial support by the National Centre for Research and Development (NCBR) within the Project POSCIS under Grant No. LIDER/09/129/L-3/11/NCBR/2012). IVF and EAK acknowlegde financial support from Adelis Foudation. N. Blaubach is acknowledged for ICP measurements. 


\section{Bibliography}

1 W. Zhao, S. Li, H. Yao, S. Zhang, Y. Zhang, B. Yang, and J. Hou, Molecular Optimization Enables over 13\% Efficiency in Organic Solar Cells, J. Am. Chem. Soc. 139 (2017), 7148-7151.

2 Z. Xiao, X. Jia, and L. Ding, Ternary organic solar cells offer $14 \%$ power conversion efficiency, Sci. Bull. 62 (2017), 1562-1564.

3 W. R. Mateker and M. D. McGehee, Progress in Understanding Degradation Mechanisms and Improving Stability in Organic Photovoltaics, Adv. Mater. 29 (2017), 1603940.

4 R. Roesch, K.-R. Eberhardt, S. Engmann, G. Gobsch, and H. Hoppe, Polymer solar cells with enhanced lifetime by improved electrode stability and sealing, Sol. Energ. Mater. Sol. Cell. 117 (2013), 59-66.

5 C. H. Peters, I. T. Sachs-Quintana, J. P. Kastrop, S. Beaupré, M. Leclerc, and M. D. McGehee, High Efficiency Polymer Solar Cells with Long Operating Lifetimes, Adv. Energ. Mater. 1 (2011), 491-494.

6 S. A. Gevorgyan, I. M. Heckler, E. Bundgaard, M. Corazza, M. Hösel, R. R. Søndergaard, G. A. dos Reis Benatto, M. Jørgensen, and F. C. Krebs, Improving, characterizing and predicting the lifetime of organic photovoltaics, J. Phys. Appl. Phys. 50 (2017), 103001.

7 N. Gasparini, M. Salvador, S. Strohm, T. Heumueller, I. Levchuk, A. Wadsworth, J. H. Bannock, J. C. de Mello, H.-J. Egelhaaf, D. Baran, I. McCulloch, and C. J. Brabec, Burnin Free Nonfullerene-Based Organic Solar Cells, Adv. Energ. Mater. 7 (2017), 1700770.

8 S. A. Gevorgyan, N. Espinosa, L. Ciammaruchi, B. Roth, F. Livi, S. Tsopanidis, S. Zufle, S. Queiros, A. Gregori, G. A. D. Benatto, M. Corazza, M. V. Madsen, M. Hosel, M. J. Beliatis, T. T. Larsen-Olsen, F. Pastorelli, A. Castro, A. Mingorance, V. Lenzi, D. Fluhr, R. Roesch, M. M. D. Ramos, A. Savva, H. Hoppe, L. S. A. Marques, I. Burgues, E. Georgiou, L. Serrano-Lujan, and F. C. Krebs, Baselines for Lifetime of Organic Solar Cells, Adv. Energ. Mater. 6 (2016), 9.

9 S. Rafique, S. M. Abdullah, K. Sulaiman, and M. Iwamoto, Fundamentals of bulk heterojunction organic solar cells: An overview of stability/degradation issues and strategies for improvement, Renew. Sustain. Energ. Rev. 84 (2018), 43-53.

10 S. A. Gevorgyan, M. V. Madsen, H. F. Dam, M. Jorgensen, C. J. Fell, K. E. Anderson, B. C. Duck, A. Mescheloff, E. A. Katz, A. Elschner, R. Roesch, H. Hoppe, M. Hermenau, M. Riede, and F. C. Krebs, Interlaboratory outdoor stability studies of flexible roll-to-roll coated organic photovoltaic modules: Stability over 10,000 h, Sol. Energ. Mater. Sol. Cell. 116 (2013), 187-196.

11 R. Roesch, T. Faber, E. von Hauff, T. M. Brown, M. Lira-Cantu, and H. Hoppe, Procedures and Practices for Evaluating Thin-Film Solar Cell Stability, Adv. Energ. Mater. 5 (2015), 24.

12 M. O. Reese, S. A. Gevorgyan, M. Jorgensen, E. Bundgaard, S. R. Kurtz, D. S. Ginley, D. C. Olson, M. T. Lloyd, P. Moryillo, E. A. Katz, A. Elschner, O. Haillant, T. R. Currier, V. Shrotriya, M. Hermenau, M. Riede, K. R. Kirov, G. Trimmel, T. Rath, O. Inganas, F. L. Zhang, M. Andersson, K. Tvingstedt, M. Lira-Cantu, D. Laird, C. McGuiness, S. Gowrisanker, M. Pannone, M. Xiao, J. Hauch, R. Steim, D. M. DeLongchamp, R. Rosch, 
H. Hoppe, N. Espinosa, A. Urbina, G. Yaman-Uzunoglu, J. B. Bonekamp, A. van Breemen, C. Girotto, E. Voroshazi, and F. C. Krebs, Consensus stability testing protocols for organic photovoltaic materials and devices, Sol. Energ. Mater. Sol. Cell. 95 (2011), 1253-1267.

13 H. Cha, J. Wu, A. Wadsworth, J. Nagitta, S. Limbu, S. Pont, Z. Li, J. Searle, M. F. Wyatt, D. Baran, J.-S. Kim, I. McCulloch, and J. R. Durrant, An Efficient, "Burn in" Free Organic Solar Cell Employing a Nonfullerene Electron Acceptor, Adv. Mater. 29 (2017), 1701156.

14 M. V. Madsen, K. Norrman, and F. C. Krebs, Oxygen- and water-induced degradation of an inverted polymer solar cell: the barrier effect, J. Photon. Energ. 1 (2011), 011104.

15 P. Cheng and X. Zhan, Stability of organic solar cells: challenges and strategies, Chem. Soc. Rev. 45 (2016), 2544-2582.

16 K. Norrman and F. C. Krebs, Lifetimes of organic photovoltaics: Using TOF-SIMS and 1802 isotopic labelling to characterise chemical degradation mechanisms, Sol. Energ. Mater. Sol. Cell. 90 (2006), 213-227.

17 H. Hintz, H. J. Egelhaaf, H. Peisert, and T. Chassé, Photo-oxidation and ozonization of poly(3-hexylthiophene) thin films as studied by UV VIS and photoelectron spectroscopy, Polymer Degrad. Stabil. 95 (2010), 818-825.

18 M. S. White, D. C. Olson, S. E. Shaheen, N. Kopidakis, and D. S. Ginley, Inverted bulkheterojunction organic photovoltaic device using a solution-derived $\mathrm{ZnO}$ underlayer, Appl. Phys. Lett. 89 (2006), 87-90.

19 S. Bertho, G. Janssen, T. J. Cleij, B. Conings, W. Moons, A. Gadisa, J. D'Haen, E. Goovaerts, L. Lutsen, J. Manca, and D. Vanderzande, Effect of temperature on the morphological and photovoltaic stability of bulk heterojunction polymer:fullerene solar cells, Sol. Energ. Mater. Sol. Cell. 92 (2008), 753-760; D. E. Motaung, G. F. Malgas, and C. J. Arendse, Insights into the stability and thermal degradation of P3HT:C60 blended films for solar cell applications, J. Mater. Sci. 46 (2011), 4942-4952.

20 B. Gholamkhass and S. Holdcroft, Toward stabilization of domains in polymer bulk heterojunction films, Chem. Mater. 22 (2010), 5371-5376.

21 M. Manceau, A. Rivaton, J.-L. Gardette, S. Guillerez, and N. Lemaître, Light-induced degradation of the P3HT-based solar cells active layer, Sol. Energ. Mater. Sol. Cell. 95 (2011), 1315-1325.

22 M. Manceau, E. Bundgaard, J. E. Carlé, O. Hagemann, M. Helgesen, R. Søndergaard, M. Jørgensen, and F. C. Krebs, Photochemical stability of $\pi$-conjugated polymers for polymer solar cells: a rule of thumb, J. Mater. Chem. 21 (2011), 4132; M. Manceau, S. Chambon, A. Rivaton, J. L. Gardette, S. Guillerez, and N. Lematre, Effects of long-term UV-Visible light irradiation in the absence of oxygen on P3HT and P3HT: PCBM blend, Sol. Energ. Mater. Sol. Cell. 94 (2010), 1572-1577.

23 S. Holdcroft, A photochemical study of poly(3-hexylthiophene), Macromolecules 24 (1991), 4834-4838.

24 S. Bertho, G. Janssen, T. J. Cleij, B. Conings, W. Moons, A. Gadisa, J. D’Haen, E. Goovaerts, L. Lutsen, J. Manca, and D. Vanderzande, Effect of temperature on the morphological and photovoltaic stability of bulk heterojunction polymer:fullerene solar cells, Sol. Energ. Mater. Sol. Cell. 92 (2008), 753-760.

25 T. Heumueller, T. M. Burke, W. R. Mateker, I. T. Sachs-Quintana, K. Vandewal, C. J. Brabec, and M. D. McGehee, Disorder-Induced Open-Circuit Voltage Losses in Organic Solar Cells During Photoinduced Burn-In, Adv. Energ. Mater. 5 (2015), 1500111. 
26 H. Hintz, H.-J. Egelhaaf, L. Lüer, J. Hauch, H. Peisert, and T. Chassé, Photodegradation of P3HT A Systematic Study of Environmental Factors, Chem. Mater. 23 (2011), 145154.

27 T. Heumueller, W. R. Mateker, A. Distler, U. F. Fritze, R. Cheacharoen, W. H. Nguyen, M. Biele, M. Salvador, M. von Delius, H.-J. Egelhaaf, M. D. McGehee, and C. J. Brabec, Morphological and electrical control of fullerene dimerization determines organic photovoltaic stability, Energ. Environ. Sci. 9 (2016), 247-256.

28 A. Distler, T. Sauermann, H.-J. Egelhaaf, S. Rodman, D. Waller, K.-S. Cheon, M. Lee, and D. M. Guldi, The Effect of PCBM Dimerization on the Performance of Bulk Heterojunction Solar Cells, Adv. Energ. Mater. 4 (2014), 1300693.

29 H. C. Wong, Z. Li, C. H. Tan, H. Zhong, Z. Huang, H. Bronstein, I. McCulloch, J. T. Cabral, and J. R. Durrant, Morphological Stability and Performance of Polymer-Fullerene Solar Cells under Thermal Stress: The Impact of Photoinduced PC60BM Oligomerization, ACS Nano 8 (2014), 1297-1308.

30 H. H. Khaligh and I. A. Goldthorpe, Failure of silver nanowire transparent electrodes under current flow, Nanoscale Res. Lett. 8 (2013), 235.

31 C. K. Chan, W. Zhao, S. Barlow, S. Marder, and A. Kahn, Decamethylcobaltocene as an efficient n-dopant in organic electronic materials and devices, Org. Electron. 9 (2008), 575-581.

32 R. Steim, F. R. Kogler, and C. J. Brabec, Interface materials for organic solar cells, J. Mater. Chem. 20 (2010), 2499-2512.

33 Ö. Usluer, M. Abbas, G. Wantz, L. Vignau, L. Hirsch, E. Grana, C. Brochon, E. Cloutet, and G. Hadziioannou, Metal Residues in Semiconducting Polymers: Impact on the Performance of Organic Electronic Devices, ACS Macro Lett. 3 (2014), 1134-1138.

34 L. A. Frolova, N. P. Piven, D. K. Susarova, A. V. Akkuratov, S. D. Babenko, and P. A. Troshin, ESR spectroscopy for monitoring the photochemical and thermal degradation of conjugated polymers used as electron donor materials in organic bulk heterojunction solar cells, Chem. Comm. 51 (2015), 2242-2244.

35 L. Ciammaruchi, F. Brunetti, and I. Visoly-Fisher, Solvent effects on the morphology and stability of PTB7:PCBM based solar cells, Sol. Energ. 137 (2016), 490-499.

36 W. C. H. Choy and D. Zhang, Solution-Processed Metal Oxides as Efficient Carrier Transport Layers for Organic Photovoltaics, Small 12 (2016), 416-431.

37 R. Betancur, Maymóc, X. Elias, Luat T. Vuong, and J. Martorell, Sputtered NiO as electron blocking layer in P3HT:PCBM solar cells fabricated in ambient air, Sol. Energ. Mater. Sol. Cell. 95 (2011), 735-739.

38 M. Wang, F. Xie, W. Xie, S. Zheng, N. Ke, J. Chen, N. Zhao, and J. B. Xu, Device lifetime improvement of polymer-based bulk heterojunction solar cells by incorporating copper oxide layer at Al cathode, Appl. Phys. Lett. 98 (2011), 2011-2014.

39 C. H. Hsieh, Y. J. Cheng, P. Jung Li, C. H. Chen, M. Dubosc, R. M. Liang, and C. S. Hsu, Highly efficient and stable inverted polymer solar cells integrated with a cross-linked fullerene material as an interlayer, J. Am. Chem. Soc. 132 (2010), 4887-4893.

40 L. Ciammaruchi, C. Wang, Y. Gao, and C. W. Tang, Delineation of degradation patterns of C60-based organic solar cells under different environments, J. Appl. Phys. 117 (2015), 245504.

41 Z. Yin, J. Wei, and Q. Zheng, Interfacial Materials for Organic Solar Cells: Recent Advances and Perspectives, Adv. Sci. 3 (2016), 1500362. 
42 A. M. Nardes, M. Kemerink, M. M. de Kok, E. Vinken, K. Maturova, and R. A. J. Janssen, Conductivity, work function, and environmental stability of PEDOT:PSS thin films treated with sorbitol, Org. Electron. 9 (2008), 727-734.

43 C. Waldauf, M. Morana, P. Denk, P. Schilinsky, K. Coakley, S. A. Choulis, and C. J. Brabec, Highly efficient inverted organic photovoltaics using solution based titanium oxide as electron selective contact, Appl. Phys. Lett. 89 (2006), 1-4.

44 D. Gao, M. G. Helander, Z. B. Wang, D. P. Puzzo, M. T. Greiner, and Z. H. Lu, C60:LiF blocking layer for environmentally stable bulk heterojunction solar cells, Adv. Mater. 22 (2010), 5404-5408.

45 G. Teran-Escobar, J. Pampel, J. M. Caicedo, and M. Lira-Cantu, Low-temperature, solution-processed, layered V2O5 hydrate as the hole-transport layer for stable organic solar cells, Energ. Environ. Sci. 6 (2013), 3088-3098.

46 M. T. Dang, L. Hirsch, and G. Wantz, P3HT:PCBM, Best Seller in Polymer Photovoltaic Research, Adv. Mater. 23 (2011), 3597-3602.

47 D. Baran, R. S. Ashraf, D. A. Hanifi, M. Abdelsamie, N. Gasparini, J. A. Rohr, S. Holliday, A. Wadsworth, S. Lockett, M. Neophytou, C. J. M. Emmott, J. Nelson, C. J. Brabec, A. Amassian, A. Salleo, T. Kirchartz, J. R. Durrant, and I. McCulloch, Reducing the efficiency-stability-cost gap of organic photovoltaics with highly efficient and stable small molecule acceptor ternary solar cells, Nat. Mater. 16 (2016), 363-369.

48 M. V. Madsen, T. Tromholt, A. Böttiger, J. W. Andreasen, K. Norrman, and F. C. Krebs, Influence of processing and intrinsic polymer parameters on photochemical stability of polythiophene thin films, Polymer Degrad. Stabil. 97 (2012), 2412-2417.

49 K. Sivula, C. K. Luscombe, B. C. Thompson, and J. M. J. Fréchet, Enhancing the Thermal Stability of Polythiophene:Fullerene Solar Cells by Decreasing Effective Polymer Regioregularity, J. Am. Chem. Soc. 128 (2006), 13988-13989.

50 P. Kumar, C. Bilen, K. Feron, X. Zhou, W. J. Belcher, and P. C. Dastoor, Enhanced regeneration of degraded polymer solar cells by thermal annealing, Appl. Phys. Lett. 104 (2014), 193905.

51 C. R. Singh, G. Gupta, R. Lohwasser, S. Engmann, J. Balko, M. Thelakkat, T. ThurnAlbrecht, and H. Hoppe, Correlation of charge transport with structural order in highly ordered melt-crystallized poly(3-hexylthiophene) thin films, J. Polym. Sci. Pt. B-Polym. Phys. 51 (2013), 943-951.

52 Z. Ding, J. Kettle, M. Horie, S. W. Chang, G. C. Smith, A. I. Shames, and E. A. Katz, Efficient solar cells are more stable: the impact of polymer molecular weight on performance of organic photovoltaics, J. Mater. Chem. A 4 (2016), 7274-7280.

53 L. H. Nguyen, H. Hoppe, T. Erb, S. Gunes, G. Gobsch, and N. S. Sariciftci, Effects of annealing on the nanomorphology and performance of poly(alkylthiophene): fullerene bulk-heterojunction solar cells, Adv. Funct. Mater. 17 (2007), 1071-1078.

54 J. Zhao, A. Swinnen, G. Van Assche, J. Manca, D. Vanderzande, and B. Van Mele, Phase Diagram of P3HT/PCBM Blends and Its Implication for the Stability of Morphology, J. Phys. Chem. B 113 (2009), 1587-1591.

55 I. T. Sachs-Quintana, T. Heumüller, W. R. Mateker, D. E. Orozco, R. Cheacharoen, S. Sweetnam, C. J. Brabec, and M. D. McGehee, Electron Barrier Formation at the OrganicBack Contact Interface is the First Step in Thermal Degradation of Polymer Solar Cells, Adv. Funct. Mater. 24 (2014), 3978-3985.

56 C. Müller, On the Glass Transition of Polymer Semiconductors and Its Impact on Polymer Solar Cell Stability, Chem. Mater. 27 (2015), 2740-2754. 
57 T. Heumueller, W. R. Mateker, I. T. Sachs-Quintana, K. Vandewal, J. A. Bartelt, T. M. Burke, T. Ameri, C. J. Brabec, and M. D. McGehee, Reducing burn-in voltage loss in polymer solar cells by increasing the polymer crystallinity, Energ. Environ. Sci. 7 (2014), 2974-2980.

58 J. U. Lee, J. W. Jung, J. W. Jo, and W. H. Jo, Degradation and stability of polymer-based solar cells, J. Mater. Chem. 22 (2012), 24265-24283.

59 A. D. de Zerio, A. Melianas, S. Rossbauer, O. Bäcke, L. Nordstierna, P. Erhart, E. Olsson, T. D. Anthopoulos, O. Inganäs, and C. Müller, High - Entropy Mixtures of Pristine Fullerenes for Solution - Processed Transistors and Solar Cells, Adv. Mater. 27 (2015), 7325-7331.

60 A. D. de Zerio and C. Müller, Glass Forming Acceptor Alloys for Highly Efficient and Thermally Stable Ternary Organic Solar Cells, Adv. Energ. Mater. (2018), 1702741.

61 J. W. Rumer, R. S. Ashraf, N. D. Eisenmenger, Z. Huang, I. Meager, C. B. Nielsen, B. C. Schroeder, M. L. Chabinyc, and I. McCulloch, Dual Function Additives: A Small Molecule Crosslinker for Enhanced Efficiency and Stability in Organic Solar Cells, Adv. Energ. Mater. 5 (2015), 1401426; J. W. Rumer and I. McCulloch, Organic photovoltaics: Crosslinking for optimal morphology and stability, Mater. Today 18 (2015), 425-435.

62 M. Drees, H. Hoppe, C. Winder, H. Neugebauer, N. S. Sariciftci, W. Schwinger, F. Schaffler, C. Topf, M. C. Scharber, Z. G. Zhu, and R. Gaudiana, Stabilization of the nanomorphology of polymer-fullerene "bulk heterojunction" blends using a novel polymerizable fullerene derivative, J. Mater. Chem. 15 (2005), 5158-5163.

63 G. Wantz, L. Derue, O. Dautel, A. Rivaton, P. Hudhomme, and C. Dagron-Lartigau, Stabilizing polymer-based bulk heterojunction solar cells via crosslinking, Polymer. Int. 63 (2014), 1346-1361.

64 Q. Burlingame, B. Song, L. Ciammaruchi, G. Zanotti, J. Hankett, Z. Chen, E. A. Katz, and S. R. Forrest, Reliability of Small Molecule Organic Photovoltaics with Electron Filtering Compound Buffer Layers, Adv. Energ. Mater. 6 (2016), 1601094.

65 D. K. Susarova, N. P. Piven, A. V. Akkuratov, L. A. Frolova, M. S. Polinskaya, S. A. Ponomarenko, S. D. Babenko, and P. A. Troshin, ESR spectroscopy as a powerful tool for probing the quality of conjugated polymers designed for photovoltaic applications, Chem. Comm. 51 (2015), 2239-2241.

66 L. Ciammaruchi, S. Penna, A. Reale, T. M. Brown, and A. Di Carlo, Acceleration factor for ageing measurement of dye solar cells, Microelectron. Reliab. 53 (2013), 279-281.

67 E. A. Katz, D. Faiman, S. M. Tuladhar, J. M. Kroon, M. M. Wienk, T. Fromherz, F. Padinger, C. J. Brabec, and N. S. Sariciftci, Temperature dependence for the photovoltaic device parameters of polymer-fullerene solar cells under operating conditions, J. Appl. Phys. 90 (2001), 5343-5350.

68 T.-A. Chen, X. Wu, and R. D. Rieke, Regiocontrolled Synthesis of Poly(3alkylthiophenes) Mediated by Rieke Zinc: Their Characterization and Solid-State Properties, J. Am. Chem. Soc. 117 (1995), 233-244.

69 S. Das, F. Herrmann-Westendorf, F. H. Schacher, E. Tauscher, U. Ritter, B. Dietzek, and M. Presselt, Controlling Electronic Transitions in Fullerene van der Waals Aggregates via Supramolecular Assembly, ACS Appl. Mater. Interfaces 8 (2016), 21512-21521; F. Herrmann, S. Engmann, M. Presselt, H. Hoppe, S. Shokhovets, and G. Gobsch, Correlation between near infrared-visible absorption, intrinsic local and global sheet resistance of poly(3,4-ethylenedioxy-thiophene) poly(styrene sulfonate) thin films, Appl. Phys. Lett. 100 (2012), 153301. 

Presselt, Influence of Interface Doping on Charge-Carrier Mobilities and Sub-Bandgap Absorption in Organic Solar Cells, J. Phys. Chem. C 119 (2015), 9036-9040.

71 M. Presselt, F. Herrmann, S. Shokhovets, H. Hoppe, E. Runge, and G. Gobsch, Subbandgap absorption in polymer-fullerene solar cells studied by temperature-dependent external quantum efficiency and absorption spectroscopy, Chem. Phys. Lett. 542 (2012), 70-73.

72 W. B. Jackson, N. M. Amer, A. C. Boccara, and D. Fournier, Photothermal deflection spectroscopy and detection, Appl. Optic. 20 (1981), 1333-1344.

73 M. T. Neukom, S. Züfle, and B. Ruhstaller, Reliable extraction of organic solar cell parameters by combining steady-state and transient techniques, Org. Electron. 13 (2012), 2910-2916.

74 S. Züfle, M. T. Neukom, S. Altazin, M. Zinggeler, M. Chrapa, T. Offermans, and B. Ruhstaller, An Effective Area Approach to Model Lateral Degradation in Organic Solar Cells, Adv. Energ. Mater. 5 (2015), 1500835.

75 R. D. McCullough and R. D. Lowe, Enhanced electrical conductivity in regioselectively synthesized poly(3-alkylthiophenes), Journal of the Chemical Society, Chem. Comm. (1992), 70-72.

76 T. A. Chen and R. D. Rieke, The first regioregular head-to-tail poly(3-hexylthiophene2,5-diyl) and a regiorandom isopolymer: nickel versus palladium catalysis of 2(5)-bromo5(2)-(bromozincio)-3-hexylthiophene polymerization, J. Am. Chem. Soc. 114 (1992), 10087-10088.

77 R. S. Loewe, S. M. Khersonsky, and R. D. McCullough, A Simple Method to Prepare Head-to-Tail Coupled, Regioregular Poly(3-alkylthiophenes) Using Grignard Metathesis, Adv. Mater. 11 (1999), 250-253.

78 A. Marrocchi, D. Lanari, A. Facchetti, and L. Vaccaro, Poly(3-hexylthiophene): synthetic methodologies and properties in bulk heterojunction solar cells, Energ. Environ. Sci. 5 (2012), 8457-8474.

79 I. Osaka and R. D. McCullough, Advances in Molecular Design and Synthesis of Regioregular Polythiophenes, Accounts Chem. Res. 41 (2008), 1202-1214.

80 C. Bracher, H. Yi, N. W. Scarratt, R. Masters, A. J. Pearson, C. Rodenburg, A. Iraqi, and D. G. Lidzey, The effect of residual palladium catalyst on the performance and stability of PCDTBT:PC 70 BM organic solar cells, Org. Electron. 27 (2015), 266-273.

81 A. I. Shames, L. N. Inasaridze, A. V. Akkuratov, A. E. Goryachev, E. A. Katz, and P. A. Troshin, Assessing the outdoor photochemical stability of conjugated polymers by EPR spectroscopy, J. Mater. Chem. A 4 (2016), 13166-13170.

82 L. N. Inasaridze, A. I. Shames, I. V. Martynov, B. Li, A. V. Mumyatov, D. K. Susarova, E. A. Katz, and P. A. Troshin, Light-induced generation of free radicals by fullerene derivatives: an important degradation pathway in organic photovoltaics?, J. Mater. Chem. A 5 (2017), 8044-8050.

83 F. Matteocci, L. Cinà, E. Lamanna, S. Cacovich, G. Divitini, P. A. Midgley, C. Ducati, and A. Di Carlo, Encapsulation for long-term stability enhancement of perovskite solar cells, Nano Energ. 30 (2016), 162-172.

84 T. J. Wilderspin, F. De Rossi, and T. M. Watson, A simple method to evaluate the effectiveness of encapsulation materials for perovskite solar cells, Sol. Energ. 139 (2016), 426-432. 
85 S. Sweetnam, K. R. Graham, G. O. N. Ndjawa, T. Heumüller, J. A. Bartelt, T. M. Burke, W. Li, W. You, A. Amassian, and M. D. McGehee, Characterization of the Polymer Energy Landscape in Polymer:Fullerene Bulk Heterojunctions with Pure and Mixed Phases, J. Am. Chem. Soc. 136 (2014), 14078-14088.

86 A. Guerrero and G. Garcia-Belmonte, Recent Advances to Understand Morphology Stability of Organic Photovoltaics, Nano-Micro Letters 9 (2016), 10.

87 F. C. Krebs, T. Tromholt, and M. Jorgensen, Upscaling of polymer solar cell fabrication using full roll-to-roll processing, Nanoscale 2 (2010), 873-886.

88 G. F. A. Dibb, M.-A. Muth, T. Kirchartz, S. Engmann, H. Hoppe, G. Gobsch, M. Thelakkat, N. Blouin, S. Tierney, M. Carrasco-Orozco, J. R. Durrant, and J. Nelson, Influence of doping on charge carrier collection in normal and inverted geometry polymer:fullerene solar cells, Sci. Rep. 3 (2013), 3335.

89 E. A. Katz, A. Mescheloff, I. Visoly-Fisher, and Y. Galagan, Light intensity dependence of External Quantum Efficiency of fresh and degraded organic photovoltaics, Sol. Energ. Mater. Sol. Cell. 144 (2016), 273-280.

90 M. T. Neukom, N. A. Reinke, and B. Ruhstaller, Charge extraction with linearly increasing voltage: A numerical model for parameter extraction, Sol. Energ. 85 (2011), 1250-1256.

91 S. Züfle, Degradation Analysis and Parameter Extraction of Organic Semiconductor Devices : Investigation by means of Complementary Measurement Techniques combined with Numerical Simulation, PhD Thesis, Karlsruhe Institute of Technology, DOI: 10.5445/IR/1000078129, 2017 (accessed 10 March 2018) .

92 F. Panzer, H. Bässler, and A. Köhler, Temperature Induced Order-Disorder Transition in Solutions of Conjugated Polymers Probed by Optical Spectroscopy, J. Phys. Chem. Lett. 8 (2017), 114-125.

93 H. Yamagata and F. C. Spano, Interplay between intrachain and interchain interactions in semiconducting polymer assemblies: The HJ-aggregate model, The Journal of Chemical Physics 136 (2012), 184901.

94 C. Müller, N. D. Zhigadlo, A. Kumar, M. A. Baklar, J. Karpinski, P. Smith, T. Kreouzis, and N. Stingelin, Enhanced Charge-Carrier Mobility in High-Pressure-Crystallized Poly(3-hexylthiophene), Macromolecules 44 (2011), 1221-1225.

95 P. Kohn, S. Huettner, H. Komber, V. Senkovskyy, R. Tkachov, A. Kiriy, R. H. Friend, U. Steiner, W. T. S. Huck, J.-U. Sommer, and M. Sommer, On the Role of Single Regiodefects and Polydispersity in Regioregular Poly(3-hexylthiophene): Defect Distribution, Synthesis of Defect-Free Chains, and a Simple Model for the Determination of Crystallinity, J. Am. Chem. Soc. 134 (2012), 4790-4805.

96 M. V. Khenkin, A. K. M, I. Visoly-Fisher, Y. Galagan, F. Di Giacomo, B. R. Patil, G. Sherafatipour, V. Turkovic, H.-G. Rubahn, M. Madsen, T. Merckx, G. Uytterhoeven, J. P. A. Bastos, T. Aernouts, F. Brunetti, M. Lira-Cantu, and E. A. Katz, Reconsidering figures of merit for performance and stability of perovskite photovoltaics, Energ. Environ. Sci. 11 (2018), 739-743. 